A Latent Transition Analysis Investigating the Nature, Stability, Antecedents, and Outcomes of Occupational Commitment Profiles for School Principals

\title{
Simon Houle
}

\author{
A Thesis \\ in the \\ Department of Psychology
}

Presented in Partial Fulfillment of the Requirements

For the Master of Arts (Psychology)

at

Concordia University

Montreal, Quebec, Canada

August 2019

(C) Simon Houle, 2019 


\section{CONCORDIA UNIVERSITY}

\section{School of Graduate Studies}

This is to certify that the thesis prepared

By: $\quad$ Simon Houle

Entitled: $\quad$ A Latent Transition Analysis Investigating the Nature, Stability, Antecedents, and Outcomes of Occupational Commitment Profiles for School Principals

and submitted in partial fulfillment of the requirements for the degree of

\section{Master of Arts (Psychology - Research Option)}

complies with the regulations of the University and meets the accepted standards with respect to originality and quality.

Signed by the final examining committee:

Chair

Dr. Andreas Arvanitogiannis

Examiner

Dr. Christian Vandenberghe

Examiner

Dr. William Michael Bukowski

Supervisor

Dr. Alexandre J.S. Morin

Approved by

Dr. Aaron Johnson

Chair of Department

Dr. André G. Roy

Dean of Faculty of Arts \& Science

Date 


\begin{abstract}
A Latent Transition Analysis Investigating the Nature, Stability, Antecedents, and Outcomes of Occupational Commitment Profiles for School Principals
\end{abstract}

Simon Houle

Considerable progress in commitment theory has been made possible by the adoption of a person-centered perspective. Such a perspective has made it possible for researchers to identify the most common combinations of Affective (AC), Normative (NC), and Continuance (CC) commitment to the organization. These combinations, or profiles, describe the various types of psychological processes depicting the ties linking employees with their organizations. However, limited research has consider commitment profiles as they relate to distinct targets of commitment, and even fewer studies have done so while adopting a longitudinal perspective. The goal of this study was to contribute to this growing literature by focusing on occupational commitment among a sample of 525 school principals ( $M_{a g e}=44.94 ; 59 \%$ females), while also adopting a longitudinal perspective to assess profile stability over a three-year period. In addition, we investigated the implications of these profiles in relation to turnover intentions, job satisfaction, work-life imbalance and psychological distress, as well as the role of relationship with other managers, involvement in decision-making, and schoolboard transformational leadership in the prediction of profile membership. Our results revealed five distinct profiles of occupational commitment, which remained identical over the course of the study and proved to be highly stable (less than a fifth of the participants transitioned to a distinct profile over time). Beneficial effects were associated with profiles dominated by AC, detrimental effects were related to the $\mathrm{CC}$-dominant profile, and we found beneficial synergistic effects of $\mathrm{NC}$ when combined with high CC in terms of job satisfaction, turnover intentions and work-life imbalance. In terms of predictions, only higher levels of relatedness with other school managers proved to predict profile membership. We discuss implications for commitment theory and practical applications of occupational commitment profiles. 


\begin{abstract}
AKNOWLEDGEMENTS
Above all, I extend my gratitude to Dr. Alexandre Morin for his guidance and support, without which this thesis would not have been possible. It is worth recognizing that I have learnt more in the last two years, under his supervision, than in the rest of my academic career combined, which speaks to his exceptional mentoring abilities. I am also grateful to all members of the Substantive Methodological Synergy lab for providing insights when needed, and fostering a productive work environment in which to exchange ideas.

Thank you also to Claude Fernet for kindly agreeing to share the data that he and his team collected, and to Bill Bukowski and Christian Vandenberghe for taking the time to serve on my committee and provide feedback for my educational benefit.

A special thanks to Karine Elalouf, who is always looking out for my well-being and making sure that I stay on track. Finally, thank you to all my friends and family for their love and support over the last two years, as they are the reason I am able to maintain a healthy work-life balance.
\end{abstract}




\section{Contribution of Authors}

This thesis was written in collaboration with Dr. Alexandre Morin, who provided continuous support and feedback, as well as guiding necessary revisions to produce a research article that is coherent and socially relevant. Dr. Claude Fernet also contributed significantly by providing a rich data set that was years in the making, allowing for research on a largely neglected population of high-level managers in the public sector. 
Table of Contents

Introduction 1

Affective, Continuance and Normative Commitment to the Occupation 3

Theoretical Rationale for Occupational Commitment Profiles 5

Profile Stability 9

Antecedents of Occupational Commitment $\quad 11$

Outcomes of Commitment Profiles 14

Methods

Participants, Data Collection, and Missing Data Procedures 17

$\begin{array}{ll}\text { Measures } & 18\end{array}$

$\begin{array}{ll}\text { Occupational Commitment } & 18\end{array}$

$\begin{array}{lr}\text { Schoolboard Transformational Leadership } & 19\end{array}$

Involvement in the Decision Process 19

Quality of Interpersonal Relationships with Other School Managers 20

$\begin{array}{ll}\text { Psychological Distress } & 20\end{array}$

$\begin{array}{ll}\text { Job Satisfaction } & 21\end{array}$

Turnover Intentions $\quad 21$

Work-life Imbalance $\quad 21$

$\begin{array}{ll}\text { Analyses } & 21\end{array}$

$\begin{array}{ll}\text { Model estimation and Missing Data } & 21\end{array}$

$\begin{array}{ll}\text { Preliminary Measurement Models } & 22\end{array}$

$\begin{array}{ll}\text { Occupational Commitment } & 23\end{array}$

$\begin{array}{ll}\text { Predictors } & 23\end{array}$

Outcomes $\quad 23$

Measurement Invariance $\quad 24$

Model Fit Assessment and Comparison $\quad 24$

Factor Scores $\quad 25$

Main Models 26

Latent Profile Analyses and Tests of Profile Similarity 26

$\begin{array}{ll}\text { Latent Transition Analyses } & 27\end{array}$

Demographic Controls and Predictors $\quad 27$

$\begin{array}{ll}\text { Outcomes } & 28\end{array}$

Model Selection and Comparison $\quad 29$

$\begin{array}{ll}\text { Results } & 30\end{array}$

Measurement Models $\quad 30$

Latent Profiles $\quad 31$

$\begin{array}{ll}\text { Latent Transitions } & 33\end{array}$

Demographic Predictors of Profile Membership $\quad 34$

Theoretical Predictors of Profile Membership $\quad 34$

Outcomes of Profile Membership $\quad 35$

$\begin{array}{ll}\text { Discussion } & 37\end{array}$

Person-Centered Implications for Commitment Theory 38

Predicting Occupational Commitment Profile Membership $\quad 40$

Outcomes of Commitment Profiles 42 
Limitations and Future Directions $\quad 45$

Concluding Remarks $\quad 47$

$\begin{array}{ll}\text { References } & 49\end{array}$

$\begin{array}{ll}\text { Appendices } & 60\end{array}$

Appendix 1: Figures $\quad 61$

1. Elbow Plot of the Information Criteria for Time 1 LPA 61

2. Elbow Plot of the Information Criteria for Time 2 LPA 61

3. Final 5-Profile Solution of Distributional Similarity 62

4. Outcome Means for the 5-Profile Distributional Similarity Model 63

Appendix 2: Tables

1. Goodness of Fit for the Measurement Models 64

2. Longitudinally Invariant Standardized Parameter Estimates for the 65 Occupational Commitment Measurement Model

3. Longitudinally Invariant Standardized Parameter Estimates for the 66 Predictor Measurement Model

4. Longitudinally Invariant Standardized Parameter Estimates for the 67 Outcomes Measurement Model

5. Reliability and Correlations for the Variables used in this Study 68

6. Results from the Latent Profile Analyses 70

7. Detailed Results from the Final Latent Profile Analytic Solution 71

8. Transitions Probabilities for the Final Latent Transition Analysis 72 Model

9. Results from the Multinomial Logistic and Multiple Regressions 73 Predicting Profile Membership

10. Time-Invariant Associations between Profile Membership and the Outcomes 
Workplace commitment has been defined by Meyer and Herscovitch (2001) as a driving force that has the potential to bind "an individual to a course of action that is of relevance to a particular target” (p. 310). This driving force can be underpinned by three different mindsets (Meyer \& Allen, 1991; Meyer, Allen, \& Smith, 1993): An emotional attachment (affective commitment - AC; e.g., Buchanan, 1974), a sense of moral obligation (normative commitment NC; e.g., Wiener, 1982) and a recognition of the costs associated with leaving one's association with the target (continuance commitment - CC; e.g., Becker, 1960; Kanter, 1968). The desirable impact of employees' commitment to their organization in terms of focal (e.g. turnover intentions) and discretionary (e.g. extra-role performance, well-being) behaviours are well documented (e.g., Meyer \& Maltin, 2010; Meyer, Stanley, Herscovitch, \& Topolnytsky, 2002). However, research considering mindsets of commitment directed at other targets, such as the occupation, is scarcer. Yet, this additional research has generally yielded similar conclusions regarding the benefits of occupational commitment, particularly $\mathrm{AC}$, in relation to a variety of focal and discretionary outcomes (e.g., Lee, Carswell, \& Allen, 2000). Importantly, the occupation is likely to represent a far more critical component of commitment for a variety of occupational groups, such as public service employees, including nurses, teachers, and physicians in countries where the state is considered the employer and where mobility across "organizations" within that state is frequent. For this reason, the restricted amount of research devoted to occupational commitment is worrisome, even though the apparent generalizability of results obtained in research on organizational commitment to the occupation is encouraging.

Another area where research is currently lacking relates to the combined effects of AC, $\mathrm{NC}$, and $\mathrm{CC}$, particularly when targets other than the organization are considered (Meyer \& Morin, 2016). Thus, despite the widespread recognition that employees' commitment to any 
specific target involves varying levels of AC, NC, and CC (Meyer \& Herscovitch, 2001), knowledge regarding the most common configurations (or profiles) of commitment mindsets is mainly limited to the organization. Yet, this research has been able to generate a few particularly noteworthy conclusions that would have been impossible, or at least difficult, to achieve using more traditional variable-centered investigations of relations between commitment mindsets and work outcomes. For instance, meta-analytic variable-centered (i.e., focused on average relations among constructs obtained in specific samples) evidence (Meyer et al., 2002) has shown AC to be systematically associated with greater benefits than $\mathrm{NC}$, whereas $\mathrm{CC}$ has been shown to be associated with weaker, or even undesirable, effects. Yet, person-centered evidence, coming from research focused on the identification of subpopulations (or profiles) of employees characterized by qualitatively distinct configurations of $\mathrm{AC}, \mathrm{NC}$, and $\mathrm{CC}$, has revealed that both $\mathrm{NC}$ and $\mathrm{CC}$ can be experienced in a very different manner depending on the way they combine with one another and with AC (e.g., Meyer \& Morin, 2016). For instance, on its own, CC describes feelings of entrapment and generally yields undesirable effects, whereas when combined with AC it does reflect feelings of investment and yields positive effects (Powell \& Meyer, 2004). Likewise, person-centered research has shown that NC rarely appears on its own, and that its combination with AC (i.e., moral commitment) seems to be particularly important in Asian societies (e.g., Morin, Meyer, McInerney, Marsh, \& Ganotice, 2015).

The present study seeks to add to this body of research by considering occupational commitment profiles among high-level public managers, a particularly neglected group of employees. More precisely, this study focuses on a sample of school principals recruited in the Canadian province of Quebec. Since these school principals are hired by the state, and routinely relocated to new schools in order to achieve the best possible match between their unique set of 
competencies and the specific needs of the school system, the occupation appeared to be a particularly relevant target of commitment to consider among this population. In addition, the present study also seeks to contribute to this body of research by documenting the construct validity and practical relevance of the identified profiles (e.g., Morin, Morizot, Boudrias, \& Madore, 2011) by: (i) adopting a longitudinal perspective (Morrow, 2011), allowing us to assess their stability over time (Morin, Meyer, Creusier, \& Biétry, 2016), and (ii) examining the associations between these profiles and a variety of theoretically relevant predictors (transformational leadership of the schoolboard, involvement in the decision making process, and quality of interpersonal relationships with other school managers) and outcomes (psychological distress, job satisfaction, and turnover intentions).

\section{Affective, Continuance and Normative Commitment to the Occupation}

Abundant variable-centered research has supported the distinctive nature (Meyer \& Parfyonova, 2010) and differential predictive validity (Meyer et al., 2002) of AC, NC, CC directed at the organization as the focal target of commitment. Yet, accumulating evidence (Lee et al., 2000; Morin, Morizot et al., 2011; Morin, Meyer et al., 2015) does suggest that results obtained in relation to organizational commitment seems to generalize to the occupation.

Generally, the benefits of AC directed at the organization have been clearly established in relation to higher levels of job satisfaction, attendance, job performance, organizational citizenship behaviours (OCB), well-being and life satisfaction, as well as lower levels of withdrawal cognitions, turnover intentions, turnover, psychological stress and distress, and workfamily conflict (Meyer \& Maltin, 2010; Meyer et al., 2002). The benefits of NC and CC are not as constant across outcomes. Thus, both NC and CC tend to be negatively associated with turnover intentions, withdrawal cognitions and turnover, whereas only NC shows a positive 
association with attendance, job performance and OCB, albeit less pronounced than that involving AC (Meyer et al., 2002). Moreover, CC has been found to either relate positively, or not at all, to employees' emotional exhaustion, strain and stress, while NC shows no relation with various indices of stress and strain (Meyer \& Maltin, 2010), but sometimes displays positive relations with emotional exhaustion (e.g., Tan \& Akhtar, 1998).

There is mounting evidence that $\mathrm{AC}$ to the occupation follows the same pattern of results as $\mathrm{AC}$ to the organization, correlating positively with job involvement and satisfaction, satisfaction with co-workers, supervisor support and autonomy, and negatively with burnout, withdrawal cognitions, turnover intentions, stress, role ambiguity and role conflict (Lee, Carswell \& Allen, 2000; Snape \& Redman, 2003; Stinglhamber, Bentein, \& Vandenberghe, 2002). Conversely, the more limited research conducted on NC and CC to the occupation reveals that these mindsets tend to be negatively related to withdrawal cognitions and turnover intentions (Irving, Coleman, \& Cooper, 1997; Snape \& Redman, 2003; Stinglhamber, Bentein, \& Vandenberghe, 2002), though results vary in terms of which of these mindsets presents the strongest relation. When considering the distinct nature of the organization and the occupation as targets of commitments, it seems logical to anticipate a possibly greater salience of $\mathrm{CC}$ in the case of the occupation, as changing one's occupation often carries a far greater burden than moving to another organization to practice the same occupation, particularly among highly specialized or trained employees. Regarding NC, just like NC to the organization has been suggested to possibly play a greater role in more collectivist cultures (Morin, Meyer, et al., 2015), NC to the occupation could also become more salient in occupations playing a socially critical role, such as teaching, nursing, or managing schools. Drawing upon the social exchange literature, it is possible to assume that part of an occupation's worth as a resource comes from the 
status that it provides to the employee (e.g., Foa \& Foa, 1974, 1980). Status, like any other resource, varies in how accessible it is (particularism) and whether it provides a tangible or symbolic benefit (concreteness) (Cropanzano \& Mitchell, 2005). For occupations associated with symbolic benefits for society, the social exchange process might thus naturally lead the employee to develop higher levels of NC toward that occupation than he or she would have developed toward another occupation.

The lack of studies looking into NC and CC to the occupation has also created a gap in knowledge pertaining to interactions and combinations amongst the mindsets of occupational commitment, which is particularly problematic considering the overwhelming evidence that organizational commitment mindsets do combine to form complex profiles tapping into widely diversified psychological states (Meyer \& Morin, 2016). Indeed, even variable-centered studies tend to demonstrate, when tested, that commitment mindsets tend to interact synergistically with one another (Gellatly et al., 2006; Johnson, Groff, \& Taing, 2009) rather than to have simple, additive, complementary effects (Meyer \& Herscovitch, 2001). This observation led Gellatly et al. (2006) to propose that each specific mindset of commitment creates a context for how the other mindsets will be experienced by an employee. For example, NC may be experienced differently if paired with high AC (moral imperative), or high CC (indebted obligation), versus low AC/NC (trapped) (Morin \& Meyer, 2016). Similarly, CC paired with high AC (invested) should also yield more beneficial work outcomes than CC alone (Meyer \& Morin, 2016; Powell \& Meyer, 2004).

\section{Theoretical Rationale for Occupational Commitment Profiles}

An early theorization of the combined effects of commitment mindsets, anchored into the three component model (TCM) of commitment (Meyer \& Allen, 1991), has been proposed by 
Meyer and Herscovitch (2001). These authors developed a rationale to propose that individual employees' commitment to their organization could theoretically follow eight distinct profiles characterized by a distinct mindset configuration. On the basis of variable-centered evidence related to relations typically obtained among commitment mindsets and outcomes, Meyer and Herscovitch suggested that the most desirable profile, from an outcome perspective, should be one in which high $\mathrm{AC}$ is combined with low NC and $\mathrm{CC}$ (AC dominant). In contrast, they proposed that the least desirable profiles should be one characterized by low AC, NC and CC (weakly committed) or by low AC/NC coupled with high $\mathrm{CC}$ (CC-dominant), thus reflecting either a lack of commitment or a feeling of entrapment. The remaining theoretical profiles are characterized by high $\mathrm{NC}$ coupled with low $\mathrm{AC} / \mathrm{CC}$ (NC dominant), or by a high level on two mindsets coupled with a low level on the other (AC/NC dominant; $\mathrm{AC} / \mathrm{CC}$ dominant; $\mathrm{NC} / \mathrm{CC}$ dominant), with a final profile characterized by a moderately high (Firmly Committed) to very high (Fully Committed) level on all three mindsets. Though all of these theoretical profiles have been empirically validated for organizational commitment, some appear to more commonly emerge across studies (Kabins, Xu, Bergman, Berry \& Willson, 2016; Meyer \& Morin, 2016). The most common of those are profiles characterized by either low (Uncommitted), or weak (Weakly Committed) scores on all three components, as well as the Firmly or Fully Committed (high scores on $\mathrm{AC}, \mathrm{NC}$, and $\mathrm{CC}$ ), $\mathrm{AC} / \mathrm{NC}$ Dominant, and CC Dominant profiles. Other profiles have also commonly emerged in research focusing on organizational commitment, including the AC Dominant, AC/CC Dominant, and CC/NC Dominant profiles.

These profiles also tend to present relatively common associations with a variety of outcomes, with research showing the most desirable profiles from an outcome perspective to be the Fully Committed, AC/NC Dominant, and AC Dominant profiles, followed by the NC/CC 
Dominant and CC Dominant profiles, and by Weakly Committed or Uncommitted profiles (e.g., Gellatly et al., 2006; Kabins et al., 2016; Meyer \& Morin, 2016; Meyer et al., 2012; Somers, 2009; Wasti, 2005). These results led Kabins et al. (2016) to propose a new profile labelling scheme, based on Meyer, Becker and van Dick's (2006) theorization of the social identity implications of the TCM. Thus, profiles dominated by AC, alone or in combination with other mindsets (Firmly or Fully Committed, AC/NC Dominant, and AC Dominant), are referred to as value-based profiles. These profiles, because their commitment is experienced as an inner desire to uphold the bond with the target, are expected to present the most desirable associations with work outcomes. In contrast, profiles driven mainly by social (NC) and/or economical (CC) obligations to the target, referred to as exchange-based profiles (NC/CC Dominant, $\mathrm{CC}$ Dominant), should relate more modestly to beneficial work outcomes. Lastly, profiles characterized by low (Weakly Committed) to very low (Uncommitted) levels of commitment across targets, referred to as displaying a weak commitment profile, should display either negative or no relations with desirable work outcomes (Kabins et al., 2016).

It is interesting to note that the few studies that have considered employees' profiles of commitment to their occupation, or to both their occupation and organization, tend to show that this taxonomy (value-based, exchange-based, or weak) of commitment profiles applies equally to the occupation. To our knowledge, only three published studies have sought to identify profiles of employees while considering their commitment to the occupation (Meyer, Morin, Stanley \& Maltin, 2019; Morin, Meyer, et al., 2015; Tsoumbris \& Xenikou, 2010). Unfortunately, only one of these studies did report a solution that was solely based on employees' mindsets of commitment to their occupations (Morin, Meyer, et al., 2015), whereas all three report profiles of employees defined based on a combination of commitment to the organization and occupation. 
In a study of Hong Kong teachers, Morin, Meyer et al. (2015) revealed that occupational commitment was best reflected according to six distinct profiles corresponding to the Weak CC Dominant, Weakly Committed, Moderately Committed, AC Dominant, AC/NC Dominant and Firmly Committed profiles previously identified for organizational commitment. In addition, when considering dual commitment profiles (combining mindsets of commitment to the organization and occupation), their results generally revealed that most profiles tend to present matching mindsets across these two targets of commitment (Meyer et al., 2019; Morin, Meyer et al. 2015; Tsoumbris \& Xenikou, 2010), a result previously reported by Morin, Morizot et al. (2011) in a study only considering employees AC to a variety of targets. In addition, it is interesting to note that, in their study of Hong Kong teachers, Morin, Meyer et al. (2015) found $\mathrm{CC}$ and/or $\mathrm{NC}$ were at least one of the two dominant mindsets of occupational commitment to the teaching profession in the majority of the identified profiles (four out of seven). Likewise, in their study of North American teacher, Meyer et al. (2019) found that NC dominated two profiles (out of five) characterized by a Full Commitment to the occupation, while CC dominated one additional profile. These results are consistent with our previous proposition that $\mathrm{CC}$ and $\mathrm{NC}$ are important mindsets to consider in relation to occupational commitment occurring in the context of socially-valued specialized professions.

On the basis of the aforementioned theoretical considerations and empirical knowledge regarding the most commonly occurring organizational commitment profiles, an observation that occupational commitment tends to follow organizational commitment in terms of profile configuration, we propose the following hypotheses.

Hypothesis 1: Occupational commitment profiles will display the following configurations: Fully or Firmly Committed, AC/NC Dominant, AC Dominant, NC/CC 
Dominant, CC Dominant, and Weakly Committed or Uncommitted.

\section{Profile Stability}

Achieving a clear understanding of employees' commitment profiles can be particularly useful from an intervention perspective, not only because most managers and practitioners have a natural tendency to think in terms of categories (Morin, Morizot et al., 2011; Zyphur, 2009), but also by providing guidance on the development of interventions targeting specific profiles of employees (Meyer \& Morin, 2016). However, the ability to rely on these categories to guide intervention requires evidence that the identified profiles generalize across contexts and over time (in the absence of intervention) for specific employees. Profiles that fluctuate or change in an unpredictable manner across contexts or situations can be, at best, considered to reflect ephemeral states of dubious utility or, at worst, unreliable categories. Regrettably, so far, evidence is lacking regarding the ability to clearly generalize occupational commitment profiles across samples and over time among specific employees.

Fortunately, evidence is quickly accumulating for the generalizability of the identified organizational commitment profiles across samples and studies through the constant emergence of the profiles mentioned earlier (Kabins et al., 2016; Meyer \& Morin, 2016). In addition, two studies have more specifically documented, via formal tests of profile similarity (Morin, Meyer et al., 2016), the generalizability of profile solutions across samples of North American and French employees (Morin, Meyer et al., 2016) or across samples of Turkish employees recruited before or after an economic crisis (Meyer, Morin, \& Wasti, 2018).

The adoption of a longitudinal perspective provides a way to go beyond simple tests of generalizability across samples to also consider stability over time in the nature of the profiles identified (within-sample stability), but also stability and change in individual employee 
membership in specific profiles (within-person stability) (Kam, Morin, Meyer, \& Topolnytsky, 2016). Yet, despite mounting evidence that organizational commitment levels are relatively stable (Lapointe, Vandenberghe \& Panaccio, 2011; Meyer, Hecht, Gill, \& Toplonytsky, 2010) or slightly decreasing (Bentein, Vandenberg, Vandenberghe, \& Stinglhamber, 2005) over time, little is known about the temporal stability of commitment profiles. In fact, a single study has looked at the within-sample stability of organizational commitment profiles among a sample of employees measured before, and after, exposure to organizational changes. In this study, Kam et al. (2016) found evidence that the identified number (configural similarity), shape (structural similarity) and within-profile variability (dispersion similarity) of profiles stayed constant over time. In addition, although the authors did not formally test for this form of stability, they also found latent profiles that had roughly the same size over time (distributional similarity). Finally, in terms of within-person stability, Kam et al. reported that only a very small number $(<3 \%)$ of employees transitioned to a distinct, yet generally similarly shaped, profile over the 8 months duration of the study. This last result supports the within-person stability of organizational commitment profiles, and suggest that these profiles might efficiently capture relatively stable inter-individual differences. Yet, this last interpretation should not be taken to mean that change in profile membership is impossible (indeed, the authors reported that management trustworthiness perceptions could predict changes in profile membership), simply that it is unlikely in the absence of intervention.

The present study was designed to similarly assess the within-sample and within-person stability of occupational commitment profiles via the adoption of a longitudinal perspective. Given the evidence provided by Kam et al. (2016) regarding the high rates of within-person stability of organizational commitment profiles over the course of a period of eight month 
encompassing the implementation of organizational changes, a longer time interval of three years was retained in the present study in order to maximize our chances of observing, and predicting, within-person changes. Yet, in light of the aforementioned evidence regarding the cross-sample generalizability and within-sample stability of organisational commitment profile, we propose the following hypotheses:

Hypothesis 2: We expect to find evidence of within-sample stability related to the number (configural similarity), shape (structural similarity), within-profile variability (dispersion similarity), and size (distributional similarity) of occupational commitment profiles over the course of a three-year period.

Hypotheses 3: We expect to find evidence of within-person stability, as evidenced by a limited number of participants who transition to a different profile over time, and by transitions occurring mainly among similarly-shaped profiles over the course of a threeyear period.

\section{Antecedents of Occupational Commitment}

The commitment literature is rich with theory regarding the psychological processes involved for commitment mindsets to strengthen and weaken over time. In particular, social exchange theory (Blau, 1964) has long been one of the key theoretical underpinning of research focusing on the determinants of workplace commitment. Indeed, social exchanges occurring between the employee and commitment targets, particularly the organization, the supervisor and the workgroup, are known to play a strong role in the emergence of commitment to these targets (Cropanzano \& Mitchell, 2005; Meyer \& Allen, 1991). At the core of social exchange theory is the idea that successful social exchanges require both parties to believe that the other party is able and willing to fulfill obligations related to the terms of the exchange. Whereas these 
obligations are readily identifiable between employees and organizations, supervisors, and work teams (Cropanzano \& Mitchell, 2005; Lavelle, Rupp, \& Brockner, 2007), they are seldom mentioned in relation to the occupation. Presumably, this is because, the occupation comes with fewer concrete obligations to uphold apart from providing the employee with the ability to practice an enjoyable and satisfactory profession, associated with a specific pay range and social status. Other obligations of relevance to the occupation are more likely handled via social exchanges with the organization, supervisor, and/or work teams. Indeed, changing the relationship with any one of these targets may create work conditions that substantively affect employees' perceived social exchanges with their occupation. As such, it may be simpler to view occupational commitment as a motivational force (Meyer, Becker, \& Vandenberghe, 2004), rather than a social exchange, when considering possible antecedents.

When considering commitment as a motivational force it becomes possible to look toward motivational theories to guide the investigation of likely antecedents of commitment profiles. For instance, Self-Determination Theory (SDT; Ryan \& Deci, 2000, 2017) proposes that employee motivation emerges in part from need-supportive work conditions helping to support the satisfaction of employees' basic need for relatedness, competence and autonomy. There is growing support that the satisfaction of these three basic needs help to foster organizational commitment, particularly AC (Morris \& Snyder 1979; Steers 1977; Steers \& Braunstein 1976; Steers \& Spencer 1977). When considering more specific work conditions that could possibly play a role in nurturing commitment via need satisfaction, research has consistently shown that transformational leadership practices enable a work context supportive of employee's ability to function autonomously, leading in turn to greater levels of autonomous motivation (Meyer et al., 2002; Gagne \& Deci, 2005; Sheldon, Turban, Brown, Barrick, \& Judge, 2003). Interestignly, this 
result has been replicated in school settings (Eyal \& Roth, 2010).

Likewise, practices aiming to support employees' involvement in key decisions and personal growth at work (i.e., competence), have also been found to support employees' AC (Morrow, 2010). Finally, exposure to positive social interactions in the workplace (relatedness) have also been found to support AC (Epitropaki, \& Martin, 2005). Although fewer studies have considered commitment profiles, these studies support these aforementioned variable-centered conclusions in showing more desirable commitment profiles to be associated with the perceived trustworthiness of upper managers (Kam et al., 2016) and with exposure to team-oriented HR practices (Meyer, Morin \& Wasti 2018).

In the present study, we seek to extend this accumulating research evidence to the consideration of occupational commitment profiles. More precisely, we consider participants' exposure to transformational leadership practices from the schoolboard (need for autonomy), involvement in key decision processes related to the exercise of one's professional role (need for competence), and perceived quality of interpersonal relationships with other school managers as members of the same occupational group (need for relatedness), as possible predictors of their likelihood of membership into the various occupational commitment profiles. Based on the theoretical perspectives of SDT, as well as on the results from previous studies of organizational commitment profiles, we propose the following hypotheses:

Hypothesis 4: Participants' perceptions of being exposed to transformational leadership practices from their schoolboard will positively predict membership into value-based profiles compared to exchange-based and weak (low or moderate) profiles.

Hypothesis 5: Participants involvement in the decision process will positively predict membership into value-based profiles compared to exchange-based and weak (low or 
moderate) profiles.

Hypothesis 6: Perceived quality of interpersonal relationships with other school managers will positively predict membership into value-based profiles compared to exchange-based and weak (low or moderate) profiles.

\section{Outcomes of Commitment Profiles}

As noted above, the benefits of employee commitment to the organization, particularly $\mathrm{AC}$, have been well-documented in the context of variable-centered studies, in relation to increasing the likelihood of desirable outcomes (job satisfaction, attendance, job performance, OCB, well-being, satisfaction, etc.), and decreasing the likelihood of undesirable ones (turnover intentions, psychological stress and distress, work-family conflict, etc.) (for reviews, see Meyer \& Maltin, 2010; Meyer et al., 2002). However, when considering occupational commitment, despite some accumulating evidence that $\mathrm{AC}$ to the occupation seems to yield benefits similar to $\mathrm{AC}$ to the organization, relations involving $\mathrm{NC}$ and $\mathrm{CC}$ are far less documented (Lee, Carswell, \& Allen, 2000; Stinglhamber, Bentein, \& Vandenberghe, 2002; Snape \& Redman, 2003). This lack of research evidence makes it harder to anticipate the likely combined impact of occupational commitment mindsets resulting from person centered studies, although the overarching similarity in results obtained in research focusing on organizational commitment with that focusing on dual commitment to the organisation and occupation, or solely on occupational commitment lead us to expect similar associations.

As a starting point in the documentation of the construct validity (e.g., Meyer \& Morin, 2016) of the identified occupational commitment profiles, we consider employee turnover intentions, which has long been considered as the key focal outcome of commitment research (Meyer \& Allen, 1991), job satisfaction as the strongest correlate of AC to the organization 
(Meyer et al., 2002), and psychological distress and work-life imbalance as newly documented critical consequences of low levels of AC and high levels of CC (Meyer \& Maltin, 2010). Taken together, these four outcomes are a good starting point to evaluate the detrimental and/or beneficial effects of different mindset configurations.

Based on the results of a recent meta-analysis of organizational commitment profiles, the lowest levels of turnover intentions tend to occur in value-based profiles, followed by exchangebased profiles, and then by weak commitment profiles (Kabins et al., 2016). However, results from recent studies indicate that the effects of mindset combinations may be more complex than originally thought. Specifically, three recent studies, one looking at organizational commitment profiles (Kam et al., 2016), and two at dual commitment profiles (Morin, Meyer et al., 2015; Meyer et al., 2019) found that profiles characterized by globally average commitment levels dominated by AC displayed equivalent, or even greater, turnover intentions than profiles characterized by globally average commitment levels dominated by CC. These results suggest that $\mathrm{CC}$ may become a more salient driver of intentions to remain than $\mathrm{AC}$ when all commitment mindsets are low or average. Although we leave the possibility that benefits to CC-dominated profiles might emerge in some circumstance as an open research question, we propose the following hypothesis:

Hypothesis 7: Turnover intentions will be lowest for members of value-based profiles, followed by the exchange-based profiles, and then by the weak (low or moderate) profiles.

In light of the strong correlations generally observed between $\mathrm{AC}$ and job satisfaction (Meyer et al., 2002), it comes as no surprise that organizational commitment value-based profiles have consistently demonstrated the highest levels of job satisfaction, followed by the exchange- 
based profiles and then by the weak profiles (Kabins et al., 2016). When considering occupational commitment, limited variable-centered studies similarly demonstrated a positive correlation between occupational AC, NC and job satisfaction (Meyer, Allen \& Smith, 1993; Irving, Coleman \& Cooper, 1997), and a negative or null correlation between CC and job satisfaction. As such, we expect job satisfaction to follow overall levels of AC, while being positively influenced by higher NC and negatively influenced by higher CC. Given the similarity of results obtained across studies of organizational and occupational commitment, we propose the following hypothesis:

Hypothesis 8: Job satisfaction will be highest for members of value-based profiles, followed by the exchange-based profiles, and then by the weak (low or moderate) profiles.

Substantive evidence from the organizational commitment literature reveals that AC relates negatively to various indicators of psychological distress, that $\mathrm{CC}$ relates positively to the same indicators, and that the relations between $\mathrm{NC}$ and distress indicators remains uncertain, oscillating between negative and null (Meyer \& Maltin, 2010, Meyer et al., 2019; Somers, 2009). Likewise, research has also tended to show that employee's perception of work interference in their personal life, hereafter referred to as work-life imbalance, tended to be negatively related to organizational commitment, particularly to AC (Emre \& De Spiegeleare, 2019; Fontinha, Easton, \& Van Laar, 2019; Geraldes, Madeira, Carvalho, \& Chambel, 2019). Despite a lack of research evidence related to how these results may translate to occupational commitment, the occupation, particularly in high level positions, differs from the organisation in not being bounded by work hours or attendance but being part of one's identity. Changing organization, when one lacks commitment to it, typically mainly involves finding an alternative organization that might better 
fulfill one's basic psychological needs. Although this is not necessarily a simple process, and is highly impacted by opportunities and investments, changing occupation is likely to be an even more costly process in high levels position, typically requiring a return to education (high personal investments) or acceptance of downgrading one's position (high personal cost). For these reasons, we argue that the stress stemming from occupational CC, particularly when experienced on its own, is likely to be more costly in terms of psychological distress and worklife imbalance than organizational CC. In addition, because this distress is not limited to working hours, but linked to one's personal identity, it is likely to impact one's life outside of work. In contrast, these $\mathrm{CC}$ perceptions, when coupled with $\mathrm{AC}$, are likely to yield benefits in terms of increasing employee's confidence in having made the right decision. In contrast, when coupled with $\mathrm{NC}$, the perceptions of high costs of leaving coupled with the impression of betraying social obligations are likely to generate at least as much distress as CC on its own. Finally, AC coupled with NC is likely to satisfy the employee's values and moral identity, reducing the burden on, and possibly enabling, other life spheres to satisfy these same needs. These various considerations lead us to propose the following hypotheses:

Hypothesis 9: Psychological distress (i.e., depression, anxiety, cognitive difficulties, and irritability) will be lowest for members of value-based profiles, followed by the exchangebased profiles, and then by the weak (low or moderate) profiles.

Hypothesis 10: Perceptions of work-life imbalance will be lowest for members of valuebased profiles, followed by the exchange-based profiles, and then by the weak (low or moderate) profiles.

\section{Method}

\section{Participants, Data Collection, and Missing Data Procedures}


The data used in this research was collected as part of a larger longitudinal study focusing on the well-being of school principals conducted in the Canadian province of Quebec (Fernet, 2011). All 2400 members of the Quebec Federation of School Principals received an invitation letter presenting the objectives of the research and a link to the online survey. Of those, 441 school principals $(18.38 \%)$ completed the questionnaire at the initial time of data collection in October 2008, and $262(10.92 \%)$ agreed to complete a follow-up questionnaire three years later, in October 2011. In total, 525 school principals $\left(M_{a g e}=44.98 ; S D_{a g e}=7.19\right)$, including $41 \%$ males and 59\% females, participated in at least one wave of data collection. On average, participants had 6.32 years of tenure $(\mathrm{SD}=5.57)$ in this function, and were principals in schools including 75.58 employees $(\mathrm{SD}=64.71)$. These principals rated the SES of their schools (on a 1 to 3 scale) an average of $1.75(\mathrm{SD}=0.71)$, mentioned working on an average of 1.83 hours (SD $=2.01$ ) of overtime per day on the weekend, and having an average of 1.58 children under charge at home (SD 1.17). In addition, 86\% reported having a spousal partner, while the remaining $14 \%$ reported being single. In terms of education, $0.6 \%$ reported having obtained an undergraduate university degree, $25.3 \%$ a diploma superior to an undergraduate university degree, $46.1 \%$ a master's degree, and $28 \%$ a doctorate degree.

\section{Measures}

All questionnaires were administered in French. English instruments for which no validated French version was available were adapted into French following a translation/backtranslation procedure involving independent bilingual translators (e.g., Gudmundson, 2009).

Occupational Commitment. Participants' commitment to their occupation was assessed using a version of the Meyer, Allen and Smith's (1993) occupational commitment questionnaire adapted and validated in French by Stinglhamber, Bentein, and Vandenberghe (2002) as part of 
extending the three-component model of commitment to five distinct foci (including the occupation). Affective Occupational Commitment (AC) was assessed using six items $\left(\alpha_{\mathrm{t} 1}=.830\right.$; $\alpha_{\mathrm{t} 2}=.840$; e.g., I am enthusiastic about my occupation as school principal). Normative Occupational Commitment (NC) was measured using six items $\left(\alpha_{\mathrm{t} 1}=.863 ; \alpha_{\mathrm{t} 2}=.858 ;\right.$ e.g., $I$ would be violating people's trust in me if I left my occupation as school principal now). Continuance Occupational Commitment (CC) was assessed using four items that define employees' perceived costs of leaving the occupation $\left(\alpha_{\mathrm{t} 1}=.773 ; \alpha_{\mathrm{t} 2}=.817\right.$; e.g., I cannot imagine leaving my occupation as school principal because of the substantial investment in learning it required of me). Responses to these items were provided on a 5-point Likert-type scale $(1=$ Completely Disagree and $5=$ Completely Agree $)$.

Schoolboard Transformational Leadership. Participants' perception of being exposed to transformational leadership practices from their schoolboard was assessed using a measure originally developed by Carless, Wearing and Mann (2000). For the purpose of the present study, the items were simply changed to refer to the schoolboard (the closest thing to a supervisor for school principals). This scale condenses seven facets of transformational leadership (vision; staff development; supportive leadership; empowerment; innovative thinking; lead by example; and charisma) into a single 7-item global measure of transformational leadership $\left(\alpha_{\mathrm{t} 1}=.934 ; \alpha_{\mathrm{t} 2}=\right.$ 940; e.g., The schoolboard communicates a clear and positive vision of the future). Responses to these items were provided on a 5-point Likert-type scale $(1=$ Completely Disagree and $5=$ Completely Agree).

Involvement in the Decision Process. Participant's participation in decisions involving their own work was assessed using five items $\left(\alpha_{\mathrm{t} 1}=.819 ; \alpha_{\mathrm{t} 2}=.822\right)$ taken from the Michigan Organizational Assessment Questionnaire (Cammann, Fichman, Jenkins, \& Klesh, 1979; Fernet, 
Lavigne, Vallerand, \& Austin, 2014). For purposes of the present study, the referent was changed to refer to the schoolboard (e.g., The schoolboard encourages me to participate in important decisions). These items were rated on a 4-point Likert type scale $(1=$ Completely Disagree and $4=$ Completely Agree). From the perspective of SDT (Ryan \& Deci, 2000), the ability for a principal to contribute to this decision-making process should lead to a greater sense of autonomy and competence need satisfaction (e.g., Fernet et al., 2014).

Quality of Interpersonal Relationships with Other School Managers. To assess the extent to which participants' felt that their need for relatedness and support was met at the level of the interpersonal relationships they shared with other school managers, we relied on a 5-item subscale $\left(\alpha_{\mathrm{t} 1}=.955 ; \alpha_{\mathrm{t} 2}=.952 ;\right.$ e.g., Presently, in my relationships with other school managers, I feel appreciated) initially developed by Richer and Vallerand (1998). These items were rated on a 5 -point rating scale $(0=$ Not at All and $4=$ Extremely $)$. This scale has been used by researchers in the past as a measure of relatedness need satisfaction (Auzoult, 2013; Brien et al., 2012) aligned with SDT (Ryan \& Deci, 2000).

Psychological Distress. Participants' psychological distress was assessed using Ilfeld's (1976) Psychiatric Symptom Index, as adapted to French by Préville, Boyer, Potvin, Perrault, and Légaré (1992). This questionnaire includes four subscales covering symptoms of depression (5 items; $\alpha_{\mathrm{t} 1}=.750 ; \alpha_{\mathrm{t} 2}=.809 ;$ e.g., I felt hopeless about the future), cognitive difficulties ( 2 items; $\alpha_{\mathrm{t} 1}=.855 ; \alpha_{\mathrm{t} 2}=.891 ;$ e.g., I had trouble remembering things $)$, anxiety ( 3 items; $\alpha_{\mathrm{t} 1}=.737$; $\alpha_{\mathrm{t} 2}=.802$; e.g., I felt fearful or afraid), and irritability ( 4 items; $\alpha_{\mathrm{t} 1}=.788 ; \alpha_{\mathrm{t} 2}=.847$; e.g., I got angry over things that are not too important). Participants were asked to indicate the frequency to which they experienced each symptom during the past week on a 4-point rating scale $(1=$ Never and $4=$ Always). 
Job Satisfaction. Participants' satisfaction with their work was assessed with a questionnaire originally developed in French by Blais, Vallerand, Pelletier, and Brière (1989) to assess life satisfaction. For purposes of the present study, the referent for this scale was changed from "life" to "job". All five items from this measure $\left(\alpha_{t 1}=.842 ; \alpha_{t 2}=.864 ;\right.$ e.g., I am satisfied with $m y$ job $)$ were rated on a 7-point Likert type scale $(1=$ Completely Disagree and $7=$ Completely Agree).

Turnover Intentions. Participants' intentions to leave their job was measured using three items originally developed by O'Driscoll and Beehr's (1994) in which participants were asked if they thought about: (i) quitting their job, (ii) looking for a new job within the next 12 months, and (iii) looking for a new occupation. One item was added to this scale to account for the influence of the current socio-economic context in Quebec on employees' turnover intentions (i.e., If the economic context was favorable, I would actively seek a new job). All four items $\left(\alpha_{t 1}\right.$ $\left.=.889 ; \alpha_{\mathrm{t} 2}=.899\right)$ were rated on a 7 -point Likert type scale $(1=$ Completely Disagree and $7=$ Completely Agree).

Work-life Imbalance. Participants' levels of work-life imbalance, reflecting the extent to which their work as a school principal interfered with other spheres of their life was assessed using five items $\left(\alpha_{\mathrm{t} 1}=.925 ; \alpha_{\mathrm{t} 2}=.935\right.$; e.g., My work interferes with the other activities in my life) originally developed in French by Vallerand, Paquet, Philippe, and Charest (2010). All items were rated on 7-point Likert type scale $(1=$ Completely Disagree and $7=$ Completely Agree).

\section{Analyses}

\section{Model Estimation and Missing Data}

All analyses were done in Mplus 8.2 (Muthén \& Muthén, 2018) using the robust 
maximum Likelihood estimator (MLR), and Full Information Maximum Likelihood (FIML) to handle missing data. FIML made it possible to estimate all models using the full sample of participants who completed at least one measurement point $(\mathrm{n}=525)$ without relying on a suboptimal quasi-listwise deletion of participants who completed a single measurement point. Statistical research has shown FIML to have a level of efficacy comparable to that of multiple imputation, but to have a greater level of efficiency in the presence of large amounts of missing data (Enders, 2010; Graham, 2009). Just like multiple imputation, FIML assumes a Missing At Random (MAR) process, which allows the missing data process to be conditioned on all variables included in the analytic model. As such, FIML is robust to attrition-related differences on all of the key study variables. Finally, to avoid model convergence on a local maxima and to maximize the replicability of the best log likelihood value, all of the main analyses (latent profile, latent transitions) were estimated with 10000 random sets of start values, each of which was allowed 200 iterations, and the 500 strongest solutions were retained for final stage optimization (Hipp \& Bauer, 2006; McLachlan \& Peel, 2000).

\section{Preliminary Measurement Models}

In order to ascertain the psychometric properties of all measures, as well as their measurement invariance (i.e., the equivalence of their psychometric properties), preliminary measurement models were first estimated. Given the complexity of the longitudinal measurements models estimated here, three separate sets of models had to be estimated for: (i) the profiles indicators themselves (AC, NC, CC), (ii) the predictors (Transformational Leadership, Involvement in Decisions, and Quality of Interpersonal Relations), and (iii) outcomes (Psychological Distress, Job Satisfaction, Turnover Intentions, and Work-life Imbalance). 
Occupational Commitment. Participants' ratings of occupational commitment were first represented via the estimation of a three-factor $(\mathrm{AC}, \mathrm{NC}, \mathrm{CC})$ confirmatory factor analytic (CFA) model at each separate time point, before combining both models into a six-factor longitudinal CFA model (with three factors per time point). At each time point, an orthogonal method factor was included to the model to account for the methodological artifact created by the negative wording of the first, second, and fifth items from the AC subscale (e.g., Zhang, Noor, \& Savalei, 2016). For the longitudinal models, a priori correlated uniquenesses were also added between matching indicators of the factors across time points in order to avoid converging on inflated stability estimates (e.g., Marsh, 2007).

Predictors. Participants' ratings on the various predictors were first represented via the estimation of a three-factor (Transformational Leadership, Involvement in Decisions, and Quality of Interpersonal Relations) CFA model at each separate time point, before combining both models into a six-factor longitudinal CFA model (with three factors per time point). As for the commitment model, a priori correlated uniquenesses were integrated between matching indicators of the factors across time points (e.g., Marsh, 2007).

Outcomes. Participants' ratings on the various predictors were first represented via the estimation of a seven-factor (Psychological Distress: Depression, Psychological Distress: Anxiety, Psychological Distress: Cognitive Difficulties, Psychological Distress: Irritability, Job Satisfaction, Turnover Intentions, and Work-life Imbalance) CFA model at each separate time point, before combining both models into a 14-factor longitudinal CFA model (with seven factors per time point). As for the previous models, a priori correlated uniquenesses were integrated between matching indicators of the factors across time points (e.g., Marsh, 2007). Due to the local non-identification of one of the Psychological Distress factors (Cognitive 
Difficulties, estimated via two items), tau-equivalence constraints were added to locally identify this factor at the centroid of the indicators (i.e., equality constraints were placed on the factor loadings of these two items; Little, Lindenberger, \& Nesselroade, 1999).

Measurement Invariance. The aforementioned longitudinal CFA models were used to test for the measurement invariance of the latent factors across time points (Meredith, 1993; Millsap, 2011). These tests were conducted in the following sequence: (i) configural invariance (same model, including the same number of factors, with no additional constraint), (ii) weak invariance (same factor loadings), (iii) strong invariance (same factor loadings and items intercepts), (iv) strict invariance (same factor loadings, items intercepts, and items uniquenesses), (v) invariance of the latent variances and covariances; (vi) latent mean invariance. The last two models involve equality constraints imposed on the most invariant model from the previous steps in the sequence. Rather than focusing on the identification of measurement biases (or differences) like the first four steps, these last steps are used to assess the presence of substantively meaningful differences over time occurring at the latent construct level. For the outcomes model, the aforementioned essentially tau-equivalent constraints were imposed after the assessment of weak invariance. Imposing these constraints prior to tests of weak invariance would make it impossible to test for weak invariance of the Psychological Distress: Cognitive Difficulties factor. Indeed, testing for weak invariance would involve constraining one factor loading (two essentially tau equivalent factor loadings) to equality over time while freeing up the factor's variance at Time 2 (thus resulting in locally equivalent models differing by 0 degrees of freedom (e.g., Morin \& Maïano, 2011).

Model Fit Assessment and Comparisons. To empirically assess the fit of all models, we report multiple statistical indices including the chi-square test of exact fit $\left(\chi^{2}\right)$, the comparative fit 
index (CFI), the Tucker-Lewis index (TLI), and the root mean square error of approximation (RMSEA) and its confidence intervals (Hu \& Bentler, 1999; Marsh, Hau, \& Grayson, 2005). However, taking into account the well-documented sample size dependency and oversensitivity to minor misspecifications of the chi-square test of exact fit, we relied on the sample-size independent goodness-of-fit indices (CFI, TLI, RMSEA) to assess model fit (Hu \& Bentler, 1999; Marsh, Hau, \& Grayson, 2005). To interpret these indicators, we relied on typical interpretational guidelines (Hu \& Bentler, 1999; Marsh, Hau, \& Grayson, 2005) suggesting that CFI and TLI values greater than .90 and .95 respectively support adequate and excellent model fit. Comparable guidelines of the RMSEA suggests to rely on values smaller than .08 and .06 respectively to support adequate and excellent model fit. For tests of measurement invariance, we rely on guidelines established by Chen (2007; also see Cheung \& Rensvold, 2002) suggesting that the invariance hypothesis can be supported when a model does not result in a decrease in CFI and TLI greater than .01, and in an increase in RMSEA greater than .015, when compared to the previous model in the sequence.

Factor Scores. Factor scores saved from these preliminary measurement models were used in the main analyses as profile indicators, predictors, and covariates. To make sure that the measures were comparable over time, these factor scores were saved from the most invariant longitudinal models from the previous sequence (Millsap, 2011), and estimated in standardized units with $M=0$ and $S D=1$. Although factor scores are not as robust to measurement errors as fully latent variables, they afford a partial control for unreliability by giving more weight to more reliable items (Skrondal \& Laake, 2001) and preserve the measurement structure (e.g., invariance) better than scale scores (Morin, Boudrias, Marsh, Madore, \& Desrumaux, 2016; Morin, Meyer et al.,2016). 


\section{Main Models}

Latent Profile Analyses and Test of Profile Similarity. The factor scores representing $\mathrm{AC}, \mathrm{NC}$, and $\mathrm{CC}$ at each time point were first used to estimate time-specific profiles of participants. More precisely, at each separate time point, we estimated Latent Profile Analyses (LPA: Lazarfeld \& Henry, 1968; Muthén, 2001) solutions including 1 to 8 profiles in which the means and the variances of the profile indicators were freely estimated in each profile (Diallo, Morin, \& Lu, 2016; Morin, Maïano, Nagengast, Marsh, Morizot \& Janosz, 2011; Peugh \& Fan, 2013). The key objective of these analyses was to verify that the same number of profiles would be identified at each time point. Once the selection of the optimal time-specific solutions, in terms of number of profiles, was completed, these two solutions were integrated into a single longitudinal LPA, which was used to conduct longitudinal tests of profile similarity over time.

These tests were realized according a sequential strategy recently proposed by Morin, Meyer et al. (2016) and adapted to the longitudinal context by Morin and Litalien (2017). The first step seeks to verify whether the same number of profiles would be identified at both time points. This step is referred to as providing a test of configural similarity, and corresponds to the results from the previous time-specific LPA. Once these two time-specific LPA solutions are combined into a single longitudinal model, equality constraints can be progressively integrated. The second step assesses the structural similarity of the solution through the inclusion of equality constraints on the means of the profile indicators across time points. This step thus verifies whether the estimated profiles retain the same shape over time. The third step assesses the dispersion similarity of the solution through the inclusion of equality constraints on the variance of the profile indicators over time. This step thus verifies whether the within-profile variability (i.e., the inter-individual differences between profile members) remains the same over time. The 
fourth step assesses the distributional similarity of the solution through the inclusion of equality constraints on the class probabilities over time. This step thus verifies whether the relative size of the profiles remains unchanged over time.

Latent Transition Analyses. The most similar model was converted to a Latent Transition Analysis (Collins \& Lanza, 2010; Nylund, Asparouhov, \& Muthen, 2007) to directly assess within-person stability and transitions in profile membership (Kam, Morin, Meyer, \& Topolnytsky, 2016). This conversion was done via the manual implementation of the auxiliary three-step approach (Asparouhov \& Muthén, 2014) advocated by Morin and Litalien (2017) for this context. This approach has the advantages of: (i) ensuring that the definition of the profiles remains unchanged when including covariates (predictors, outcomes; e.g., Diallo, Morin, \& Lu, 2017); (ii) preserving the complete similarity of the longitudinal LPA solution while also estimating profile transitions over time. In technical terms, this approach relies on the class probability information from the final longitudinal LPA model (step 1). This information is then used to define nominal profile indicators, using the classification logits to maintain a probabilitybased classification (step 2). This converted solution is then used for other analyses (step 3).

Demographic Controls and Predictors. Demographic controls and predictors of profile membership were directly integrated to this LTA model via a multinomial logistic regression link function. In terms of demographics controls, we considered participants' sex (coded $0=$ Female and $1=$ Male), age (in years), level of education ( $0=$ undergraduate university degree, 1 $=$ higher than undergraduate university degree but lower than a master's degree; $2=$ master's degree; 3 = doctorate degree), relationship status (in a spousal relationship or not), number of children at charge in the household environment, tenure in the current function (in years), and average number of overtime hours worked per day on the weekend. We also considered 
participants' reports of the number of employees in their schools and estimates of the school SES ( 1 = Favorable, 2 = Average, and 3 = Unfavorable). For demographic controls, three alternative models were first estimated and contrasted (Ciarrochi, Morin, Sahdra, Litalien, \& Parker, 2017; Gillet et al., 2018). First, relations with profile membership were freely estimated across time points, and allowed to vary as a function of Time 1 profile membership (in order to assess the possible role of controls on specific profile transitions). Second, relations with profile membership were freely estimated across time points, but not across Time 1 profiles. Third, the predictive similarity of the model was tested by constraining relations to be the same over time. The same sequence of tests was then repeated with the predictors. An additional, null effects model, was also estimated for the demographic controls in order to verify whether their inclusion to the analyses really resulted in an improvement in model fit. In this model, all relations between demographics and the likelihood of profile membership are fixed to be zero.

Results from multinomial logistic regressions are interpreted as the log odds of membership in one profile compared to another. However, we also report odd ratios $(O R)$, which reflect the likelihood of belonging to a target profile compared to a comparison profile as a function of a one unit increase in the predictor. For example, an $O R$ of 3 indicates that participants are three time more likely to belong to the target profile compared to the comparison profile with every increase of one raw unit in the predictor. $O R$ s lower than 1 reflect a reduction in the likelihood of membership to the target profile versus the comparison profile per one unit increase in the predictor (e.g. $O R=.9$ equated to the likelihood of belonging to the target profile being reduced by $10 \%$ per every unit increase in the predictor).

Outcomes. Outcomes were also directly integrated to the final LTA model. Timespecific outcome measures were specified as related to profile membership at the matching time 
point. Mean-level differences were tested in a single step using the multivariate delta method (Raykov \& Marcoulides, 2004). Following Morin, Meyer et al. (2016), two models were contrasted in which profile-to-outcomes associations were either allowed to differ across time points or constraints to equality across time points.

Model Selection and Comparison. To determine the optimal number of profiles present at each time point, it is first important to consider the meaning, theoretical conformity, and statistical adequacy of the solution (Bauer \& Curran, 2003; Marsh, Lüdtke, Trautwein, \& Morin, 2009; Muthén, 2003). A variety of statistical indices can also be used to guide this process (McLachlan \& Peel, 2000): (i) the Akaïke (1987) Information Criterion (AIC), (ii) the Consistent AIC (CAIC; Bozdogan, 1987), (iii) the Bayesian Information Criterion (BIC; Schwartz, 1978), (iv) the sample-size Adjusted BIC (ABIC; Sclove, 1987), (v) the adjusted Lo, Mendel and Rubin's (2001) Likelihood Ratio Test (aLMR), and (iv) the Bootstrap Likelihood Ratio Test (BLRT McLachlan \& Peel, 2000). A lower AIC, CAIC, BIC, and ABIC value suggests a better-fitting solution. A statistically significant $p$ value on the aLMR and BLRT supports the added value of a solution relative to one including fewer profiles. Finally, the entropy indicates the precision with which the cases are classified into the various profiles, and provides a useful summary of classification accuracy (ranging from 0 to 1 ).

Statistical simulation studies demonstrated the utility of the CAIC, BIC, ABIC and BLRT, but not that of the AIC and ALMR (e.g., Diallo, Morin, \& Lu, 2016, 2017; Henson, Reise, \& Kim, 2007; Nylund, Asparouhov, \& Muthén 2007; Peugh \& Fan, 2013; Tein, Coxe, \& Cham, 2013; Tofighi \& Enders, 2008; Yang, 2006). We thus report these two indicators to ensure complete disclosure, but will not use them to guide model selection. A recent simulation study (Diallo et al., 2017) also suggests that the BIC and CAIC should be privileged when the 
classification accuracy is high (e.g., entropy $\geq .800$ ), and that the ABIC and BLRT should be favored when it is low (e.g., entropy $\leq .600$ ). In addition, all of these tests are heavily influenced by sample size (Marsh et al., 2009). For this reason, they often keep on suggesting adding profiles to the solution. When this happens, the point at which indicators reach a plateau on a graphical representation (referred to as an elbow plot) can be used to guide model selection (Morin, Maïano et al., 2011). Finally, when testing profile similarity or contrasting alternative predictive models, Morin, Meyer et al. (2016) suggest that at least two indices out of the CAIC, BIC, and ABIC should be lower for the more "similar" model to be supported.

\section{Results}

\section{Measurement Models}

Goodness-of-fit results for the series of preliminary models testing the longitudinal invariance of occupational commitment (AC, $\mathrm{NC} \& \mathrm{CC}$ ), predictors (involvement in decision process, leadership, and interpersonal relations), and outcomes (job satisfaction, turnover intentions, and psychological distress) are available in Table 1. These results confirm the full longitudinal invariance of all constructs. All three configural models fit the data well (CFI \& TLI >.900, RMSEA <.06), and subsequent models did not show a decline in CFI or TLI, or increase in RMSEA exceeding the recommended interpretation guidelines $(\Delta \mathrm{CFI} \leq .010 ; \Delta \mathrm{TLI} \leq .010$; $\triangle \mathrm{RMSEA} \leq .015$; and overlapping RMSEA confidence intervals). On this basis, the latent means invariant models were retained, and factors scores were saved from these models to use as profile indicators, predictors, and outcomes. A distinct advantage of retaining a latent means invariant model is that the grand mean in this model is set to 0 , with a variance of 1 , which allows for the profile indicators to be interpreted as deviations from the sample mean in standardized units (Meyer \& Morin, 2015). The final parameter estimates for the latent means invariant models are 
available in Tables 2 to 4 , and correlations for all variables included in the present study are available in Table 5, alongside reliability coefficients. Overall, all factors were correctly defined as shown by acceptable factor loadings $\left(M_{|\lambda|}=.756\right)$ and strong composite reliability coefficients ( $\omega$; McDonald, 1970): (a) affective commitment $\left(M_{|\lambda|}=.657 ; \omega=.842\right)$; (b) normative commitment $\left(M_{|\lambda|}=.718 ; \omega=.867\right) ;(\mathrm{c})$ continuance commitment $\left(M_{|\lambda|}=.710 ; \omega=.814\right) ;(\mathrm{d})$ relations with personnel $\left(M_{|\lambda|}=.899 ; \omega=.889\right)$; (e) transformational leadership $\left(M_{|\lambda|}=.824 ; \omega=\right.$ $.937)$; (f) involvement in decision process $\left(M_{|\lambda|}=.685 ; \omega=.925\right)$; $(\mathrm{g})$ turnover intentions $\left(M_{|\lambda|}=\right.$ $.828 ; \omega=.897) ;(\mathrm{h})$ job satisfaction $\left(M_{|\lambda|}=.742 ; \omega=.860\right)$; (i) depression $\left(M_{|\lambda|}=.655 ; \omega=.792\right)$; (j) cognitive disturbance $\left(M_{|\lambda|}=.881 ; \omega=.874\right)$; (k) anxiety $\left(M_{|\lambda|}=.722 ; \omega=.766\right)$; (l) irritability $\left(M_{|\lambda|}=.716 ; \omega=.810\right) ;(\mathrm{m})$ work-life imbalance $\left(M_{|\lambda|}=.848 ; \omega=.930\right)$.

\section{Latent Profiles}

The fit indices for The LPA models estimated separately at both time points are reported in Table 6, and graphically represented in Figure 1 and 2. The entropy is consistently high (close to, or greater than .800 ), suggesting that greater attention should be paid to the CAIC and BIC as opposed to the ABIC and BLRT. However, as can be seen in both elbow plots, all indices seem to follow similar tendencies, and to keep on decreasing until reaching the 8-profile solution. Yet, their decrease seems to reach a first plateau around 3 profiles, and a second more pronounced one around 5 profiles at both time points. Solutions including 5 profiles, together with adjacent 4- and 6-profile solutions were thus inspected more attentively. A first noteworthy observation is that these solutions already displayed a high level of similarity across time points, providing early evidence of configural similarity. Furthermore, adding a fifth profile to the solution clearly enriched the results at both Time 1 and Time 2 through the addition of a well-defined and meaningfully distinct profile in terms of shape (corresponding to Profile 2, described below). On 
the other hand, adding a sixth profile simply resulted in the arbitrary division of one of the existing profiles into smaller ones characterized by less than $1 \%$ of the sample at Time 2 . For this reason, the 5-profile solution was retained at both time points for tests of longitudinal similarity.

The results from these tests of profile similarity are reported in the middle section of Table 6. When compared to the initial model of configural similarity, the next model of structural similarity resulted in lower values for the CAIC and BIC, thus supporting the idea that profiles had the same structure over time. Likewise, decreases in the values of the CAIC and BIC also supported the dispersion (same level of within-profile variability), and distributional (same profile sizes) similarity of the solution over time. These results support our second hypothesis.

This model of distributional similarity was thus retained for further stages of analyses and for interpretation. The detailed parameter estimates from this solution are reported in Table 7, and are graphically represented in Figure 3. The first profile is characterized by average levels of AC, and by very low levels of NC and CC. This Low AC Dominant (i.e., we use Low to reflect the fact that global levels of commitment remain low across mindsets in this profile, and to contrast it with Profile 4 where AC levels are above average) profile corresponds to $12.5 \%$ of the sample. The second profile is characterized by very low levels of AC, average levels of NC and high levels of CC. This CC Dominant (or Trapped) profile is the smallest and corresponds to $7.7 \%$ of the sample. The third profile is characterized by average levels of AC, NC and CC. This Moderately Committed profile is the largest, and corresponds to $34.6 \%$ of the sample. The fourth profile is characterized by high levels of $\mathrm{AC}$, and low levels of $\mathrm{NC}$ and $\mathrm{CC}$. This $A C$ Dominant (or Emotionally Committed) profile corresponds to $17.5 \%$ of the sample. Finally, the fifth profile is characterized by moderately high levels of $\mathrm{AC}$, and very high levels of $\mathrm{NC}$ and $\mathrm{CC}$. This $\mathrm{NC} / \mathrm{CC}$ Dominant (or Indebted) profile is the second largest and corresponds to $27.8 \%$ of the 
sample. In sum, our results revealed the presence of two value based profiles (Low AC Dominant and $A C$ Dominant), two exchange based profiles (NC/CC Dominant, CC Dominant), and one Moderately Committed profile, thus supporting our first hypothesis, as well as the salient role of $\mathrm{NC}$ and $\mathrm{CC}$ in the definition of a subset of those profiles.

\section{Latent Transitions}

This final longitudinal LPA solution of distributional similarity was then converted to an LTA, using the manual 3-step approach in order to examine within-person stability in profile membership. The within-person transition probabilities associated with this LTA are reported in Table 8. These results first show that the Low AC Dominant (1) profile was the least stable, with only $22 \%$ of the school directors initially corresponding to this profile remaining in this profile three years later. Rather, school directors belonging to this Low AC Dominant (1) profile had a high probability of transitioning upward to the similarly-shaped $A C$ Dominant (4) profile (64.1\%), and small probabilities of transitioning downward to the Moderately Committed (3: $10.3 \%$ ) or $C C$ Dominant (2: $3.6 \%$ ) profiles. Likewise, school directors belonging to the $A C$ Dominant (4) profile had a high probability of transitioning downward to the similarly-shaped Low AC Dominant (1) profile (30.2\%), and a lower probability of transitioning to the Moderately Committed (3) profile (10.8\%). However, this AC Dominant (4) profile had a higher rate of stability (59\%) than the Low AC Dominant (1) profile (22\%). Finally, the remaining profiles (2: CC Dominant; 3: Moderately Committed; 5: NC/CC Dominant) showed a very high level of stability ranging from $97.2 \%$ (profile 3 ) to $100 \%$ (profiles 2 and 5) over time. Taking into account the differences in profile size, these results show that $19.5 \%$ of the school principals transitioned to a distinct profiles over the three-year period. Taken together, these results indicate that transitions do indeed occur for some school directors, but that these transitions are limited to 
profiles dominated by AC, and more frequent among similarly shaped profiles. Otherwise, these results support the stability of the remaining profiles over time, thus providing partial support to our third hypothesis.

\section{Demographic Predictors of Profile Membership}

In order to investigate the possible need to include demographic characteristics (sex, age, tenure, number of personnel, school SES, education, relationship status and number of children) as controlled variables in the following analyses, these variables were first included as predictors of profile membership to the LTA model of distributional similarity. The results associated with the four alternative models estimated using these demographic predictors are reported in the second half of Table 6 . These results showed that the null effects model resulted in the lowest values on all information criteria, consistent with a lack of relation between these variables and the likelihood of membership into any of the profiles. This conclusion is also consistent with the examination of the parameter estimates associated with the other models. These variables were thus not retained for subsequent analyses.

\section{Theoretical Predictors of Profile Membership}

The results from the alternative models estimated to tests the effects of our theoretical predictors (quality of interpersonal relationships, transformational leadership, and involvement in decision-making processes) and participants' likelihood of profile membership are also reported in the second half of Table 6 . These results showed that the model of predictive similarity, in which the effects of the predictors on profile membership were set to be equivalent over time and not to play a role in the prediction of specific profile transitions, resulted in the lowest values for all information criteria. This model was thus retained for interpretation, and results from the multinomial logistic regressions estimated as part of this model are reported in Table 9. 
As shown in Table 9, neither participants' assessment of the schoolboard transformational leadership or of their own involvement in decision making was found to have any impact on their likelihood of membership into any of the profiles, thus failing to support Hypotheses 4 and 5. However, the quality of their interpersonal relations with other school managers was found to share multiple substantial associations with their likelihood of membership into multiple profiles. More precisely, participants reporting better, or more satisfactory, relationships had a higher likelihood of membership into the $N C / C C$ Dominant (5) profile relative to the Low AC Dominant (1) and CC Dominant (2) profiles. Likewise, better relationships were associated with a greater likelihood of membership into the Low AC Dominant (1), Moderately Committed (3) and AC Dominant (4) profiles relative to the $C C$ Dominant (2) profile. Lastly, higher relationship quality was also associated with a greater likelihood of membership into the $A C$ dominant (4) profile relative to the Low AC Dominant (1) and Moderately Committed (3) profiles. These results thus partially support Hypothesis 6, with better relationships with other school managers increasing the odds of belonging to the $N C / C C$ dominant profile compared to the low AC dominant profile

\section{Outcomes of Profile Membership}

As shown in the bottom section of Table 6 , the model of explanatory similarity resulted in the lowest value on all information criteria, and was thus supported by the data and retained for interpretation. The results from this model are reported in Table 10, and graphically illustrated in Figure 4. First, three of the psychological distress indicators (i.e., depression, anxiety, and anger) follow identical patterns of associations with the commitment profiles. More precisely, levels on these three indicators are highest in the CC Dominant (2) profile, followed by the Moderately Committed (3) and NC/CC dominant (5), which do not differ from one 
another, and then by the Low AC Dominant (1) and $A C$ Dominant (4) profiles, which also do not differ from one another. Levels of cognitive disturbance, the remaining psychological distress indicator, is equally high in the CC Dominant (2), Moderately Committed (3) and NC/CC Dominant (5) profiles, and lowest in the Low AC Dominant (1) and AC Dominant (4) profiles. Taken together, these results offer partial support for Hypothesis 9, with value-value based profiles scoring lower on psychological distress as expected, but exchange-based profiles displaying greater or equal psychological distress when compared to the Moderately Committed profile.

In terms of job satisfaction, the highest levels were equally observed in the $A C$ Dominant (4), NC/CC dominant (5), and Low AC Dominant (1) profiles, followed by the Moderately Committed (3) profile, and then by the CC Dominant (2) profile. These results thus partially support Hypothesis 8 , showing that value-based profiles tended to display higher levels of job satisfaction than one of the exchange-based profiles and the Moderately Committed profile. However, the $N C / C C$ Dominant profile displayed as much job satisfaction as the value-based profiles and significantly more than its exchange-based counterpart (CC Dominant), hinting at the possible synergistic effect of normative commitment when paired with high continuance commitment.

Levels of turnover intentions were highest in the CC Dominant (2) profile, and lowest in the $N C / C C$ Dominant (5) profile which displayed statistically lower levels of turnover intentions that the Moderately Committed (3) profile, but not than the value based profiles. These results partially support Hypothesis 7, showing the value-based profiles, alongside the $\mathrm{NC} / \mathrm{CC}$ dominant profile, as having the lowest turnover intentions, and the CC Dominant profile the highest. Once again, these results illustrate the synergistic beneficial effect of $\mathrm{NC}$ when paired with high CC. 
Finally, the highest levels of work-life imbalance were found to be associated with the CC Dominant (2) profile, followed by the $N C / C C$ dominant (5) profile, and then by the remaining three profiles, which were statistically equivalent apart from the Moderately Committed (3) profile having higher levels than the Low AC Dominant (1) profile. These results thus partially support Hypothesis 10, showing value-based profiles to present the lowest levels of work-life imbalance. However, contrary to our expectations, the Moderately Committed profile presented lower levels of work-life imbalance than the exchanged based profiles, suggesting that high continuance commitment may be driving work-life imbalance, while high NC could help to partially reduce this imbalance in the presence of High CC.

\section{Discussion}

Despite abundant research having been conducted in order to document employees’ profiles of commitment to their organization among non-managerial employees, only limited research had previously adopted such a person-centered approach to the study of occupational commitment, and none had done so among samples of managerial employees. Our study sought to address these limitations by relying on a person-centered framework in order to empirically identify occupational commitment profiles among a sample of school principals, allowing for a long overdue investigation into the combined influence of occupational commitment mindsets on a series of organizationally-salient (i.e., turnover intentions and job satisfaction) and individually-relevant (i.e. psychological distress and work-life imbalance) outcomes. Moreover, answering the repeated call for longitudinal research in organizational psychology (Avey, Luthans, \& Mhatre, 2008; Meyer \& Morin, 2016; Wang et al., 2017), this study provides evidence of longitudinal similarity in the nature of the identified occupational commitment profiles, whilst also demonstrating the persistence of membership into similarly shaped profiles 
for managers. In doing so, this study thus supported the practical and theoretical usefulness of adopting a person-centered approach to study commitment (Zyphur, 2009; Meyer \& Morin, 2016; Morin, Morizot et al., 2011). Finally, by incorporating theoretically-driven antecedents of the identified occupational commitment profiles, this study also demonstrated the benefits of ensuring quality interpersonal relationships at work amongst high-level managers, hence providing an avenue for intervention.

\section{Person-Centered Implications for Commitment Theory}

In line with our first hypothesis, we found that occupational commitment was best represented via five distinct profiles generally matching those reported among staff employees in the study of organizational commitment (Kabins et al., 2016; Meyer \& Morin, 2016). Two of these profiles could be considered to be value-based (Low AC Dominant and AC Dominant), two more could be considered to be exchange based (CC Dominant and NC/CC Dominant), whereas a last profile displayed a weaker pattern of commitment (Moderately Committed). Interestingly, two of these profiles (AC Dominant and Moderately Committed) also match those previously reported by Morin, Meyer et al. (2015) among a sample of Hong Kong teachers. This similarity of results obtained across targets of commitments, adds to the building research evidence suggesting that similar psychological mechanisms may underpin employees' commitment to their organizations and occupations.

Also matching our expectations, we found that $\mathrm{NC}$ and/or CC played a dominant role in the definition of two out of the five profiles, with $35.5 \%$ of our sample belonging to one of these profiles. This observation adds to previous research evidence collected among samples of teachers (Morin, Meyer, et al., 2015; Meyer et al., 2019) to support the idea that NC and CC might be particularly salient when the target of the commitment is a socially-valued (NC) 
specialized (CC) occupations. Indeed, $\mathrm{CC}$ to a particular occupation is likely to vary as a function of the employee's perceived ability to generalize their training, skills, and knowledge to other occupations, which is likely to linearly decrease as a function of the level of specialization and length of training required in a specific occupation. Likewise, socially-valued occupations, through the provision of a specific social status to employees (e.g., Foa \& Foa, 1974, 1980), are also likely to help in nurturing NC. Moreover, those employees who develop a moral obligation (i.e., high NC) to a socially-valued occupation may do so before they even start practicing this occupation. Thus, for socially-valued occupations requiring a long training process (e.g., physicians, judges, school principals, etc.), mutually-reinforcing relations might emerge whereby increasing $\mathrm{NC}$ levels might in turn lead to increasing CC levels. Interestingly, four of the five profiles identified in the present study displayed similar levels of NC and CC, suggesting some degree of interdependence of these two mindsets for the current sample. This observation is consistent with Meyer et al. (1993) report of a high degree of association between these mindsets in their initial study of occupational commitment, as well as with the person-centered results previously reported regarding teachers' occupational commitment profiles (Meyer et al., 2019; Morin, Meyer et al., 2015). In contrast, the remaining profile was solely dominated by CC. These results and interpretations suggest that, at least among socially-valued specialized occupations, nurturing the emergence of a moral bond to the occupation early on in the training process might help to nurture commitment more generally and to avoid the emergence of a CC-Dominant profile later on. Obviously, these speculations regarding the role of $\mathrm{NC}$ and $\mathrm{CC}$ in the emergence of commitment during early training experiences should be more thoroughly investigated in future studies.

In addition, and supporting our second hypothesis, the number, structure, dispersion, and 
relative size of these profiles were found to be virtually unchanged over the span of a three-year period. Furthermore, and supporting our third hypothesis, our results also revealed a very high level of within-person stability in profile membership over time. Indeed, only $19.5 \%$ of the participants transitioning to another profile over time, and those who did so systematically transitioned to a similarly-shaped profile. As expected, $75.4 \%$ of all transitions were limited to the similarly shaped AC Dominant and Low AC Dominant profiles, with a greater percentage of employees transitioning upwards into the $A C$ Dominant profile ( $9.64 \%$ of the entire sample), as opposed to downwards into the Low AC Dominant profile (5.06\% of entire sample). This observation suggests that the intensity of commitment might be more malleable over time in value-based profiles, supporting the idea that targeting $\mathrm{AC}$ for intervention may indeed be worthwhile (Kam et al., 2016; Meyer et al., 2019; Morin, Meyer, et al., 2015). In contrast, membership into value versus exchange-based profiles might be harder to modify, as shown by the fact that only $3.9 \%$ of the total sample transitioned out of a value-based profile into either of the Moderately Committed or CC-Dominant profiles. Finally, the fact that none of the employees belonging to the $C C$ Dominant and NC/CC Dominant profiles at the beginning of the study transitioned to a different profile three years later also reinforce our speculations regarding the salience of NC and CC among socially-valued specialized occupations. Overall, these results regarding the within-sample and within-person stability of the identified profiles support the idea that these profiles reflect relatively persistent psychological states (Gellatly et al., 2006), possibly impacted by dispositional factors (e.g., personality), and that can be used to guide intervention (Meyer \& Morin, 2016), while the observation of (more limited) within-person changes does also support the idea that change is possible.

\section{Predicting Occupational Commitment Profile Membership}


Supporting past research on organizational commitment (Epitropaki, \& Martin, 2005) and partially supporting Hypothesis 6, our results suggests that exposure to an environment allowing employees to experience positive social relationships, and thus supporting their basic need for relatedness, could be beneficial in terms of occupational commitment. More precisely, school principals who reported greater satisfaction in their relationships with other managers presented lower odds of belonging to the Trapped profile relative to all other profiles, and increased odds of membership into the $A C$ Dominant and NC/CC Dominant profiles (both of which have higher AC, NC and CC) relative to the low AC Dominant profile. These observations suggest that healthy work relationships may help to nurture commitment profiles characterized by high levels of affective attachment to one's occupation, or by a strong sense of responsibility (NC/CC). Considering that high-level managers have less opportunities to interact with peers of a similar hierarchical level than a typical employees, making sure that a functional communication network exists to facilitate positive social interactions between these employees should be a priority for anyone interested in improving AC accompanied, or not, by a strong sense of work responsibilities $(\mathrm{NC} / \mathrm{CC})$.

Contrary to our expectations, expressed within Hypotheses 4 and 5, our results failed to demonstrate any form of relations between employees' perceptions of being exposed to transformational leadership practices from their schoolboard or of being sufficiently involved in the decision-making process, and their likelihood of profile membership. Given past empirical research evidence supporting the role of similar practices in the prediction of organizational commitment (e.g., Meyer et al., 2002; Meyer \& Maltin, 2010; Morrow, 2010), this result was unexpected. Yet, the present research also focused on high-level managers, who, by definition, possess a substantial level of independence and autonomy and may, for this reason, feel slightly 
disconnected from what happens at the schoolboard level. As such, the present results suggest that schoolboard-level practices do not appear to play a substantive role in school principals' daily operations, at least not to the extent of being able to impact their commitment to their occupation. Indeed, social exchange theory could lead us to expect stronger relationships between isomorphic (i.e., related to matching targets) variables (Blau, 1964; Cropanzano \& Mitchell, 2005; Lavelle et al., 2007), suggesting that schoolboard practices might have a far greater impact on school principals commitment to the schoolboard itself, rather than to their occupation. Likewise, proximal determinants related more directly to schools principals daily actions, such as perhaps their perceptions of their own ability to lead (need for competence) or of being impeded or supported in their actions by governmental policies or union representatives (need for autonomy) could possibly play a greater role in driving their occupational commitment. Clearly, these possibilities should be more thoroughly investigated in future research.

Another explanation for these results comes from the fact that we only considered the additive effects of the predictors treated as independent variables, when researchers have recently demonstrated that a balance between the three basic needs may be just as important as having elevated levels on any single one (Sheldon \& Niemec, 2006). Although this proposition has so far been supported in relation to employees' need satisfaction (Gillet, Morin, Choisay, \& Fouquereau, in press; Gillet, Morin, Huart, Colombat, \& Fouquerau, 2019; Tóth-Király, Bőthe, Orosz, \& Rigó, 2018), it has yet to be more systematically tested in relation to work-related need supporting and thwarting work conditions (e.g., Tóth-Király, Morin, Bőthe, Orosz, \& Rigó, 2018), as well as in relation to the prediction of commitment profiles. Clearly, this is another avenue that might prove profitable for future research.

\section{Outcomes of Commitment Profiles}


From an outcomes perspective, our results generally supported Hypotheses 7 to 10 in demonstrating the benefits associated with membership into the value based profiles, particularly the $A C$ Dominant one, in relation to all outcomes. Indeed, the $A C$ Dominant profile presented the lowest levels of psychological distress (together with the Low AC Dominant profile), turnover intentions (together with the Low AC Dominant and NC/CC Dominant profiles), and work-life imbalance (together with the Low AC Dominant profile), coupled with the highest levels of job satisfaction (together with the Low AC Dominant and NC/CC Dominant profiles). These results thus add to the already abundant empirical research evidence demonstrating the benefits of AC (e.g., Lee et al., 2000; Meyer et al., 2002; Meyer \& Maltin, 2010), and of membership into ACdominated commitment profiles (e.g., Meyer \& Morin, 2016; Meyer et al., 2019; Morin, Meyer et al. 2015), for a wide range of outcome measures.

However, our results regarding the outcomes implications of the exchange-based and weaker profiles did not completely follow our expectations, expressed via Hypotheses 7 to 10 . More precisely, these hypotheses followed Kabins et al. (2016) recommendations to differentiate value-based profiles (dominated by AC, alone or in combination), exchange-based profiles (dominated by $\mathrm{NC}$ and/or CC), and weaker (not dominated by any mindset) profiles, based on the assumption that profiles corresponding to each of these categories would tap into similar psychological processes. Although our results supported this assertion in relation to the valuebased profiles, they failed to support it in relation to the remaining profiles. Thus, although we expected the least desirable outcome levels to be associated with profiles characterized by a weaker type of commitment, the Moderately Committed profile did not fully match this expectation. Indeed, this profile presented lower levels of psychological distress (depression, anxiety, and anger), turnover intentions, and work-life imbalance, but higher levels of job 
satisfaction, than the $C C$ Dominant profile. Arguably, part of the reason for these results could be that the Moderately Committed profile lied at the upper limit of Kabins et al. (2016) weaker category of commitment profiles, as it was characterized by average levels of commitment across mindsets, rather than truly low levels. As such, this profile might have corresponded to a hybrid between Kabins et al. (2016) value-based and weaker commitment profiles.

More unexpected was the observation that one of the exchange-based profiles, the $C C$ Dominant one, systematically presented the least desirable levels on all outcomes (higher levels of psychological distress, turnover intentions, and work-life imbalance, and lower levels of job satisfaction), whereas the other one, the $N C / C C$ Dominant profile, presented outcomes levels that were either as desirable as those observed in the value-based profiles (job satisfaction, turnover intentions), or at least better than those observed in the CC Dominant one (psychological distress, work life imbalance). Taken together, these results call into question the validity of the profile classification scheme proposed by Kabins et al. (2016) when transposed to occupational commitment, at least with regards to the exchange-based profiles. More precisely, these results first suggest that profiles dominated solely by CC might reflect psychological feelings of entrapment likely to lead to a variety of undesirable outcomes (Meyer, \& Herscovitch, 2001), an interpretation that matches the results, and a more extensive labeling scheme, obtained in research focusing on profiles of organizational commitment (Meyer \& Morin, 2016).

Perhaps more importantly, these results also suggest that the meaning of CC changes when combined to high levels of NC to reflect a form of moral bond or feelings of indebtedness (Meyer \& Morin, 2016) carrying far more desirable outcomes for employees. Our results support this assertion, as well as previous claims that the main benefits of $\mathrm{NC}$ are likely to be synergistic in nature (Meyer \& Parfyonova, 2010), at least in terms of job satisfaction and turnover 
intentions. Yet, these benefits do not appear to generalize to all outcomes. In particular, although the $N C / C C$ Dominant profile did fare better than the $C C$ Dominant one in terms of work-life imbalance levels, these levels remained substantially lower in this profile relative to the others. This last observation does suggest that although there are clear advantages to displaying such a moral bond to one's occupation, these advantages never completely match those associated with a purely value-based orientation to one's occupation.

To summarize, these results confirm the beneficial effects of belonging to a value-based profile (Kabins et al., 2016), while also demonstrating the often-overlooked importance of NC's synergistic effect on work outcomes (Meyer \& Parfyonova, 2010). In addition, these results also support our initial expectations regarding the likely role, and salience, of $\mathrm{NC}, \mathrm{CC}$, and their combination, for specialized employees occupying socially valued occupations. In this context $\mathrm{CC}$, when experienced on its own, appear to create a heavy burden due to an understanding of the important costs associated with leaving the occupation. In contrast, an awareness of these costs, when it is coupled with an impression of being invested in a socially important mission, appears to help allay the risks associated with these feelings of entrapment.

\section{Limitations and Future Directions}

A first limitation of the current study is related to our inability to assess the generalizability of the results beyond the current sample of French-Canadian school principals. The fact that our profiles match those obtained from prior dual-commitment studies (Meyer et al., 2019; Morin, Meyer, et al., 2015) is encouraging, but these studies also focused on a similar occupation (teachers) to the one considered here. More studies are needed across a broader range of occupations to establish cross-sample stability of the identified profiles to distinct occupational and cultural groups. 
In particular, although some of our interpretations invoke the social prestige and level of specialization associated with the school principal occupation, these speculations require verification in the context of studies considering a far wider range of occupations varying along these two possibly crucial dimensions. In addition, it would appear critical for these future studies to consider a much wider range of predictors designed to better capture the psychological processes underpinning these effects at different stages of employees' career.

In terms of prediction, the limited range of effects associated with predictors considered in the context of the present study should not be taken as contradicting SDT expectations (Ryan \& Deci, 2017) regarding the role of the work environment characteristics acting to support employees' basic psychological needs for autonomy, competence and relatedness, as key drivers of motivational states such as commitment. Indeed, our results did support the beneficial role of interpersonal relationships (i.e., need for relatedness) as a predictor of membership into more desirable commitment profiles. However, the lack of effects associated with the remaining predictors (schoolboard transformational leadership and involvement in decisions) might indicate that these measures, referring to schoolboard practices, could have failed to capture critical components of basic need satisfaction for school principals. Clearly, future research considering a wider range of predictors (such as principals' levels of self-efficacy, or feelings of being impeded or supported in their work by governmental policies or union representatives) is required to more thoroughly investigate these questions.

Our study is also limited by its sole reliance on self-reported measures, and would thus have benefited from more objective measures, such as actual turnover data, objective measures of school performance, and/or a combination of self-reported and informant-reported measures. Lastly, any study employing a longitudinal perspective faces a difficult interpretation of time as a 
variable of interest, one that merits investigation and replication. The current study focused on a relatively long-time interval, three years, based on the a priori expectation that the nature of occupational commitment profiles should persist for long periods of times, while also maximising the chances of observing employee transitions between profiles. However, using large time intervals also creates the possibility that employees could have transitioned back and forth between profiles throughout this three-year period, rendering the current conclusions regarding within-profile stability imprecise at best. Thus far, evidence for within-profile stability is limited to the current study (occupational commitment), and to that of Kam et al. (2016; organizational commitment) who found within-profile stability over an eight-month period. More studies are needed to explore within-profile stability of commitment profiles, using different time intervals, or possibly, more than two time-points in the LTA. Importantly, although we found no evidence that the predictors considered here could play a role in influencing profile transitions, future studies should look deeper into psychological, organizational, and even familial changes occurring over time which could possibly help to understand the key drivers of profile transitions.

\section{Concluding Remarks}

It is somewhat disconcerting, when one stops to think about the implications of choosing the occupation over the organization when studying employee commitment, that academics have chosen to focus their attention so narrowly on the latter. Presumably, this is due to the market value of improving organizational commitment for both the public and private sector. Yet, from a social perspective, occupational commitment lies at the core of bigger societal issues such as labor shortages in specific domains (e.g., teachers, physicians, nurses) and systematic employee discontent across organizations dealing with the same occupation (e.g. nurses working in various 
hospitals). For judges, nurses, teachers, politicians, soldiers, firefighters and police officers, to name but a few socially vital occupations, the decision to follow these specific vocational paths is likely to come from individuals' early identification with the core values, principles, and objectives of these occupations. From this perspective, it appears important for education systems, and society as a whole, to provide the context necessary for this process of occupational identification to flourish in a positive manner early on in the training and work trajectories of these individuals. Yet, our results suggest that changes remain possible even later in the career, and that nurturing positive social relationships at work might help. Although the search for actionable levers of intervention should remain a research priority, especially if society is to maintain an adequate influx of properly committed employees to these occupations, these early results are encouraging. In this regard, we hope the current study will help to guide future commitment research efforts aiming to achieve a better understanding of these key processes. 


\section{References}

Akaike, H. (1987). Factor analysis and AIC. Psychometrika, 52, 317-332.

Asparouhov, T., \& Muthén, B.O. (2014). Auxiliary variables in mixture modeling: Three-step approaches using Mplus. Structural Equation Modeling, 21, 1-13.

Auzoult, L. (2013). The mediating role of the sense of relatedness and task cohesion in the relation between psychological power distance and efficiency of a working ream. Psychology, 4, 741-743.

Avey, J. B., Luthans, F., \& Mhatre, K. H. (2008). A call for longitudinal research in positive organizational behavior. Journal of Organizational Behavior, 29, 705-711.

Bauer, D.J., \& Curran, P.J. (2003). Distributional assumptions of growth mixture models overextraction of latent trajectory classes. Psychological Methods, 8, 338-363.

Becker, H. S. (1960). Notes on the concept of commitment. American Journal of Sociology, 66, $32-42$.

Bentein, K., Vandenberghe, C., Vandenberg, R., \& Stinglhamber, F. (2005). The role of change in the relationship between commitment and turnover: A latent growth modeling approach. Journal of Applied Psychology, 90, 468-482.

Blais, M. R., Vallerand, R. J., Pelletier, L. G., \& Brière, N. M. (1989). L'échelle de satisfaction de vie: Validation canadienne-française du "Satisfaction with Life Scale." [The satisfaction scale: Canadian-French validation of the Satisfaction with Life Scale]. Canadian Journal of Behavioural Science / Revue canadienne des sciences du comportement, 21, 210-223.

Blau, P.M. (1964). Exchange and power in social life. New York, NY: Wiley.

Bozdogman, H. (1987). Model Selection and Akaike's information criterion (AIC): The general 
theory and its analytical extensions. Psychometrika, 52, 345-370.

Brien, M., Forest, J., Mageau, G. A., Boudrias, J., Desrumaux, P., Brunet, L. \& Morin, E. M. (2012). The Basic Psychological Needs at Work Scale: Measurement invariance between Canada and France. Applied Psychology: Health and Well-Being, 4, 167-187.

Buchanan, B. (1974). Building organizational commitment: The socialization of managers in work organizations. Administrative Science Quarterly, 19, 533-546.

Cammann, C., Fichman, M., Jenkins, D., \& Klesh, J. (1979). The Michigan Organizational Assessment Questionnaire. Unpublished manuscript. Institute for Social Research, University of Michigan, Ann Arbor, MI.

Carless, S. A., Wearing, A. J., \& Mann, L. (2000). A short measure of transformational leadership. Journal of Business and Psychology, 14, 389-405.

Collins, L. M., \& Lanza, S. T. (2009). Latent class and latent transition analysis. New York, NY: Wiley.

Cropanzano, R., \& Mitchell, M. S. (2005). Social exchange theory: An interdisciplinary review. Journal of Management, 31, 874-900.

Diallo, T.M.O, Morin, A.J.S., \& Lu, H. (2016). Impact of misspecifications of the latent variance-covariance and residual matrices on the class enumeration accuracy of growth mixture models. Structural Equation Modeling, 23, 507-531.

Diallo, T.M.O., Morin, A.J.S. \& Lu, H. (2017). The impact of total and partial inclusion or exclusion of active and inactive time invariant covariates in growth mixture models. Psychological Methods, 22, 166-190.

Emre, O., \& De Spiegeleare, S. (2019). The role of work-life balance and autonomy in the relationship between commuting, employee commitment and well-being. The 
International Journal of Human Resource Management. Advance online publication, doi: $10.1080 / 09585192.2019 .1583270$

Enders, C. K. (2010). Applied missing data analysis. New York, NY: Guilford.

Epitropaki, O., \& Martin, R. (2005). From ideal to real: A longitudinal study of the role of implicit leadership theories on leader-member exchanges and employee outcomes. Journal of Applied Psychology, 90, 659-676.

Eyal, O., \& Roth, G. (2011). Principals' leadership and teachers' motivation: Self-determination theory analysis. Journal of Educational Administration, 49, 256-275.

Fernet, C. (2011). Development and validation of the Work Role Motivation Scale for school principals (WRMS-SP). Educational Administration Quarterly, 47, 307-331.

Fernet, C., Lavigne, G., Vallerand, R.J., \& Austin, S. (2014). Fired up with passion: Investigating how job autonomy and passion predict burnout and turnover. Work \& Stress, 28, 270-288.

Foa, U. G., \& Foa, E. B. (1974). Societal structures of the mind. Springfield, IL: Charles C Thomas.

Foa, U. G., \& Foa, E. B. (1980). Resource theory: Interpersonal behavior as exchange. In K. J. Gergen \& M. S. Greenberg \& R. H. Willis (Eds.), Social exchange: Advances in theory and research. New York, NY: Plenum

Fontinha, R., Easton, S., \& Van Laar, D. (2019). Overtime and quality of working life in academics and nonacademics: The role of perceived work-life balance. International Journal of Stress Management, 26, 173-183

Gagne, M. \& Deci, E. L. (2005) Self-determination theory and work motivation. Journal of Organizational Behavior, 26, 331-62. 
Geraldes, D., Madeira, E., Carvalho, V. S., \& Chambel, M. J. (2019). Work-personal life conflict and burnout in contact centers: The moderating role of affective commitment. Personnel Review, 48, 400-416.

Gellatly, I. R., Meyer, J. P., \& Luchak, A. (2006). Combined effects of the three commitment components on focal and discretionary behaviors: A test of Meyer and Herscovitch's propositions. Journal of Vocational Behaviour, 69, 331-345.

Gillet, N., Morin, A. J. S., Choisay, F., \& Fouquereau, E (In Press). A person-centered representation of basic need satisfaction balance at work. Journal of Personnel Psychology.

Gillet, N., Morin, A. J. S, Huart, I., Colombat, P., \& Fouquereau, E. (2019). The forest and the trees: Investigating the globality and specificity of employees' basic need satisfaction at work. Journal of Personality Assessment. Advanced online publication, doi: $10.1080 / 00223891.2019 .1591426$

Graham, J. W. (2009). Missing data analysis: Making it work in the real world. Annual Review of Psychology, 60, 549-576.

Gudmundson, E. (2009). Guidelines for translating and adapting psychological instruments. Nordic Psychology, 61, 29-45.

Henson, J.M., Reise, S.P., \& Kim, K.H. (2007). Detecting mixtures from structural model differences using latent variable mixture modeling: A comparison of relative model fit statistics. Structural Equation Modeling, 14, 202-226.

Hipp, J. R., \& Bauer, D. J. (2006). Local solutions in the estimation of growth mixture models. Psychological Methods, 11, 36-53.

Hu, L.-T., \& Bentler, P.M. (1999). Cutoff criteria for fit indexes in covariance structure analysis: 
Conventional criteria versus new alternatives. Structural Equation Modeling, 6, 1-55.

Irving, P. G., Coleman, D. F., \& Cooper, C. L. (1997). Further assessment of a three-component model of occupational commitment: Generalizability and differences across occupations. Journal of Applied Psychology, 82, 444-452.

Johnson, R. E., Groff, K. W., \& Taing, M. U. (2009). Nature of the interactions among organizational commitments: Complementary, competitive or synergistic? British Journal of Management, 20, 431-447.

Kabins, A. H., Xu, X., Bergman, M. E., Berry, C. M., \& Willson, V. L. (2016). A profile of profiles: A meta-analysis of the nomological net of commitment profiles. Journal of Applied Psychology, 101, 881-904.

Kam, C., Morin A. J. S., Meyer, J. P., \& Topolnytsky, L. (2016). Are commitment profiles stable and predictable? A latent transition analysis. Journal of Management, 42, 1462-1490.

Kanter, R. M. (1968). Commitment and social organization: A study of commitment mechanisms in utopian communities. American Sociological Review, 33, 499-517.

Lavelle, J.J., Rupp, D.E., \& Brockner, J. (2007). Taking a multifoci approach to the study of justice, social exchange, and citizenship behavior: The target similarity model. Journal of Management, 33, 841-66.

Lee, K., Carswell, J.J., \& Allen, N.J. (2000). A meta-analytic review of occupational commitment: Relations with person- and work-related variables. Journal of Applied Psychology, 85, 799-811.

Little, T.D., Lindenberger, U., \& Nesselroade, J.R. (1999). On selecting indicators for multivariate measurement and modeling with latent variables: When "good" indicators are bad and "bad" indicators are good. Psychological Methods, 4, 192-211. 
Lubke, G. H., \& Muthén, B. (2005). Investigating population heterogeneity with factor mixture models. Psychological Methods, 10, 21-39.

Marsh, H. W. (2007). Application of confirmatory factor analysis and structural equation modeling in sport/exercise psychology. In G. Tenenbaum \& R. C. Eklund (Eds.), Handbook of sport psychology (pp. 774-798). New York, NY: Wiley.

Marsh, H. W., Hau, K.-T., \& Grayson, D. (2005). Goodness of Fit in Structural Equation Models. In A. Maydeu-Olivares \& J.J. McArdle (Eds.), Contemporary psychometrics (pp. 275-340). Mahwah, NJ: Erlbaum.

Marsh, H.W., Lüdtke, O., Trautwein, U., \& Morin, A.J.S. (2009). Classical latent profile analysis of academic self-concept dimensions: Synergy of person- and variable-centered approaches to theoretical models of self-concept. Structural Equation Modeling, 16, 191-225.

McDonald, R.P. (1970). Theoretical foundations of principal factor analysis, canonical factor analysis, and alpha factor analysis. British Journal of Mathematical \& Statistical Psychology, 23, 1-21.

McLachlan, G., \& Peel, D. (2000). Finite mixture models. New York, NY: Wiley.

Meredith, W. (1993). Measurement invariance, factor analysis and factorial invariance. Psychometrika, 58, 525-543.

Meyer, J. P., \& Allen, N. J. (1991). A three-component conceptualization of organizational commitment. Human Resource Management Review, 1, 61-89.

Meyer, J. P., \& Allen, N. J. (1997). Commitment in the workplace: Theory, research, and application. Thousand Oaks, CA: Sage.

Meyer, J.P., Allen, N.J., \& Smith, C.A. (1993). Commitment to organizations and occupations: Extension and test of a three-component conceptualization. Journal of Applied 
Psychology, 78, 538-551.

Meyer, J. P., Becker, T. E., \& van Dick, R. (2006). Social identities and commitments at work: Toward an integrative model. Journal of Organizational Behavior, 27, 665-683.

Meyer, J. P., Hecht, T. D., Gill, H., \& Toplonytsky, L. (2010). Person-organization (culture) fit and employee commitment under conditions of organizational change: A longitudinal study. Journal of Vocational Behavior, 76, 458-473.

Meyer, J. P., \& Herscovitch, L. (2001). Commitment in the workplace: Toward a general model. Human Resource Management Review, 11, 299-326.

Meyer, J. P., \& Maltin, E. R. (2010). Employee commitment and well-being: A critical review, theoretical framework and research agenda. Journal of Vocational Behavior, 77, 323-337.

Meyer, J.P., \& Morin, A. J. S. (2016). A person-centered approach to commitment research: Theory, research, and methodology. Journal of Organizational Behavior, 36, 584-612.

Meyer, J. P., Morin, A. J. S., Stanley, L. J., \& Maltin, E. R. (2019). Teachers' dual commitment to the organization and occupation: A person-centered investigation. Teaching and Teacher Education, 77, 100-111.

Meyer, J. P., Morin, A. J., \& Wasti, S. A. (2018). Employee commitment before and after an economic crisis: A stringent test of profile similarity. Human Relations, 71, 1204-1233.

Meyer, J. P., \& Parfyonova, N. M. (2010). Normative commitment in the workplace: A theoretical analysis and re-conceptualization. Human Resource Management Review, 20, $283-294$.

Meyer, J. P., Stanley, D. J., Herscovitch, L., \& Topolnytsky, L. (2002). Affective, continuance, and normative commitment to the organization: A meta-analysis of antecedents, correlates, and consequences. Journal of Vocational Behavior, 61, 20-52. 
Meyer, J. P., Stanley, L. J., \& Parfyonova, N. M. (2012). Employee commitment in context: The nature and implication of commitment profiles. Journal of Vocational Behavior, 80, 116.

Millsap, R.E. (2011). Statistical approaches to measurement invariance. New York, NY: Taylor \& Francis.

Morin, A.J.S., Boudrias, J.-S., Marsh, H.W., Madore, I., \& Desrumaux, P. (2016). Further reflections on disentangling shape and level effects in person-centered analyses: An illustration aimed at exploring the dimensionality of psychological health. Structural Equation Modeling, 23, 438454.

Morin, A. J. S., \& Litalien, D. (2017). Webnote: Longitudinal tests of profile similarity and latent transition analyses. Montreal, QC: Substantive Methodological Synergy Research Laboratory.https://smslabstats.weebly.com/uploads/1/0/0/6/100647486/lta_distributional _similarity_v02.pdf

Morin, A.J.S., \& Maïano, C. (2011). Cross-validation of the very short form of the Physical SelfInventory (PSI-VS): Invariance across genders, age groups, ehtnicities and weigth statuses. Body Image, 8, 404-410.

Morin, A.J.S., Maïano, C., Nagengast, B., Marsh, H.W., Morizot, J., \& Janosz, M. (2011). Growth mixture modeling of adolescents trajectories of anxiety: The impact of untested invariance assumptions on substantive interpretations. Structural Equation Modeling, 18, 613-648.

Morin, A. J. S., Meyer, J. P., Creusier, J., \& Biétry, F. (2016). Multiple-group analysis of similarity in latent profile solutions. Organizational Research Methods, 19, 231-254.

Morin, A.J.S., Meyer, J.P., McInerney, D. M., Marsh, H.W., \& Ganotice, F. (2015). Profiles of 
dual commitment to the occupation and organization: Relations to wellbeing and turnover intentions. Asia Pacific Journal of Management, 32, 717-744.

Morin, A.J.S., Morizot, J., Boudrias, J.-S., \& Madore, I. (2011). A multifoci person-centered perspective on workplace affective commitment: A latent profile/factor mixture analysis. Organizational Research Methods, 14, 58-90.

Morris, J. H., \& Koch, J. L. (1979). Impact of role perceptions on organizational commitment, job involvement, and psychosomatic illness among three vocational groupings. Journal of Vocational Behavior, 14, 88-101.

Morrow, P. C. (2011). Managing organizational commitment: Insights from longitudinal research. Journal of Vocational Behavior 79, 18-35.

Muthén, B. O. (2001). Latent variable mixture modeling. In G. Marcoulides\& R. Schumacker (Eds.), New developments and techniques in structural equation modeling (pp. 1-33). Mahwah, NJ: Erlbaum.

Muthén, B.O. (2003). Statistical and substantive checking in growth mixture modeling: Comment on Bauer and Curran (2003). Psychological Methods, 8, 369-377.

Muthén, B. O., \& Muthén, L. K. (2000). Integrating person-centered and variable-centered analyses: Growth mixture modeling with latent trajectory classes. Alcoholism: Clinical and Experimental Research, 24, 882-891.

Nylund, K. L., Asparouhov, T., \& Muthen, B. (2007). Deciding on the number of classes in latent class analysis and growth mixture modeling: A Monte Carlo simulation study. Structural Equation Modeling, 14, 535-569.

Peugh, J., \& Fan, X. (2013). Modeling unobserved heterogeneity using latent profile analysis: A Monte Carlo simulation. Structural Equation Modeling, 20, 616-639. 
Powell, D. M., \& Meyer, J. P. (2004). Side-bet theory and the three-component model of organizational commitment. Journal of Vocational Behavior, 65, 157-177.

Préville, M., Boyer, R., Potvin, L., Perrault, C., \& Légaré. G. (1992). La détresse psychologique: détermination de la fiabilité et de la validité de la mesure utilisée dans l'Enquête Santé Québec [Psychological distress: The reliability and validity of the measure used in the Quebec Health study]. Les Cahiers de la Recherche 7, Enquête Santé Québec 87, Gouvernement du Québec, Ministère de la Santé et des Services Sociaux. http://www.santecom.qc.ca/Bibliothequevirtuelle/santecom/35567000006905.pdf

O'Driscoll, M. P., \& Beehr, T. A. (1994). Supervisor behaviors, role stressors and uncertainty as predictors of personal outcomes for subordinates. Journal of Organizational Behavior, $15,141-155$.

Richer, S. F., \& Vallerand, R. J. (1998). Construction and validation of the need to belong scale. European Review of Applied Psychology, 48, 129-137.

Ryan, R. M., \& Deci, E. L. (2000). Self-determination theory and the facilitation of intrinsic motivation, social development, and well-being. American Psychologist, 55, 68-78.

Schwartz, G. (1978). Estimating the dimension of a model. The Annals of Statistics, 6, 461-464. Sclove, L. (1987). Application of model-selection criteria to some problems in multivariate analysis. Psychometrika, 52, 333-343.

Siemsen, E., Roth, A., \& Oliveira, P. (2010). Common method bias in regression models with linear, quadratic, and interaction effects. Organizational Research Methods, 13, 456-476.

Sheldon, K., \& Niemiec, C. (2006). It's not just the amount that counts: Balanced need satisfaction also affects well-being. Journal of Personality and Social Psychology, 91, $331-341$. 
Sheldon, K. M., Turban, D. B., Brown, K. G., Barrick, M. R. and Judge, T. A. (2003). Applying self-determination theory to organizational research. Research in Personnel and Human Resources Management, 22, 357-94.

Snape, E., \& Redman, T. (2003). An evaluation of a three-component model of occupational commitment: Dimensionality and consequences among United Kingdom human resource management specialists. Journal of Applied Psychology, 88, 152-159.

Somers, M., J. (2009). The combined influence of affective, continuance and normative commitment on employee withdrawal. Journal of Vocational Behavior 74, 75-81.

Steers, R. M. (1977). Antecedents and outcomes of organizational commitment. Administrative Science Quarterly, 22, 46-56.

Steers, R. M., \& Braunstein, D. N. (1976). A behaviorally-based measure of manifest need in work settings. Journal of Vocational Behavior, 9, 251-266.

Steers, R. M., \& Spencer, D. G. (1977). The role of achievement motivation in job design. Journal of Applied Psychology 62: 472-479.

Stinglhamber, F., Bentein, K., \& Vandenberghe, C. (2002). Extension of the three-component model of commitment to five foci. European Journal of Psychological Assessment, 18, $123-138$.

Tan, D. S. K., \& Akhtar, S. (1998). Organizational commitment and experienced burnout: An exploratory study from a Chinese cultural perspective. International Journal of Organizational Analysis, 6, 310-333.

Tein, J.-Y., Coxe, S., \& Cham, H. (2013). Statistical power to detect the correct number of classes in latent profile analysis. Structural Equation Modeling, 20, 640-657.

Tofighi, D., \& Enders, C. (2008). Identifying the correct number of classes in growth mixture 
models. In G.R. Hancock \& K.M. Samuelsen (Eds.), Advances in latent variable mixture models (pp. 317-341). Charlotte, NC: Information Age.

Tóth-Király, I., Bőthe, B., Orosz, G., \& Rigó, A. (2018). On the importance of balanced need fulfillment: A person-centered perspective. Journal of Happiness Studies. Advance online publication, doi 10.1007/s10902-018-0066-0

Tóth-Király, I., Morin, A.J.S., Bőthe, B., Orosz, G., \& Rigó, A. (2018). Investigating the multidimensionality of need fulfillment: A bifactor exploratory structural equation modeling representation. Structural Equation Modeling, 25, 267-286.

Tsoumbris, P., \& Xenikou, A. (2010). Commitment profiles: The configural effects of the forms and foci of commitment on work outcomes. Journal of Vocational Behavior, 77, 401-411.

Vallerand, R.J., Paquet, Y., Philippe, F.L., \& Charest, J. (2010). On the role of passion for work in burnout: A process model. Journal of Personality, 78, 289-312.

Wang, M., Beal, D. J., Chan, D., Newman, D. A., Vancouver, J. B., \& Vandenberg, R. J. (2017). Longitudinal research: A panel discussion on conceptual issues, research design, and statistical techniques. Work, Aging, \& Retirement, 3, 1-24.

Wiener, Y. (1982). Commitment in organizations: A normative view. Academy of Management Review, 7, 418-428.

Yang, C. (2006). Evaluating latent class analyses in qualitative phenotype identification. Computational Statistics \& Data Analysis, 50, 1090-1104.

Zhang, X., Noor, R., \& Savalei, V. (2016). Examining the effect of reverse worded items on the factor structure of the seed for cognition scale. PloS one, 11, e0157795.

Zyphur, M. (2009). When mindsets collide: Switching analytical mindsets to advance organizational science. Academy of Management Review, 34, 677-688. 
Appendices 


\section{Appendix 1: Figures}

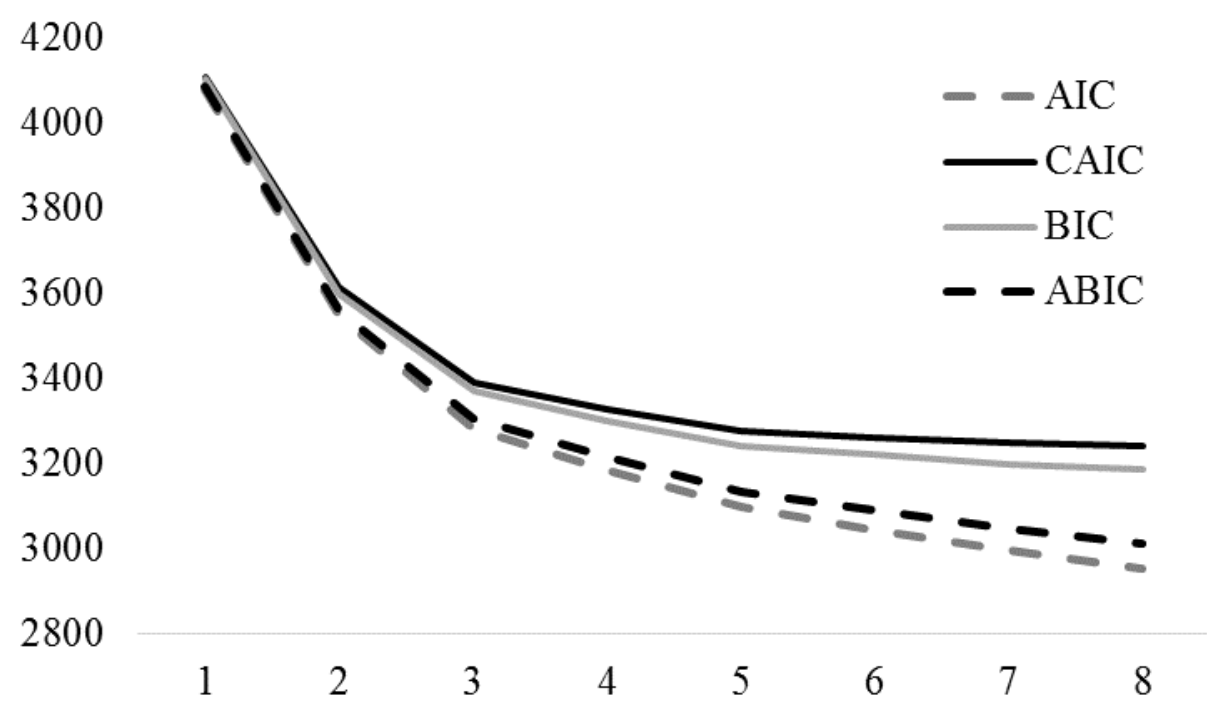

Figure 1. Elbow plot of the information criteria for the Time 1 latent profile analyses.

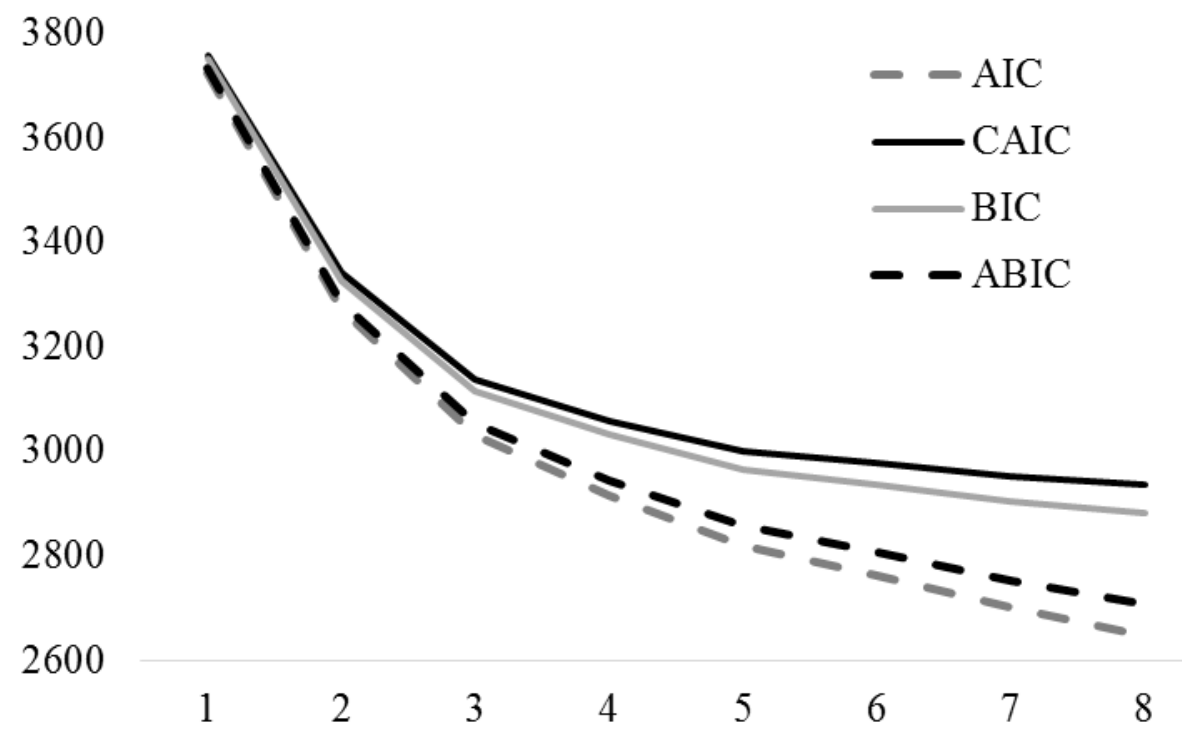

Figure 2. Elbow plot of the information criteria for the Time 2 latent profile analyses. 


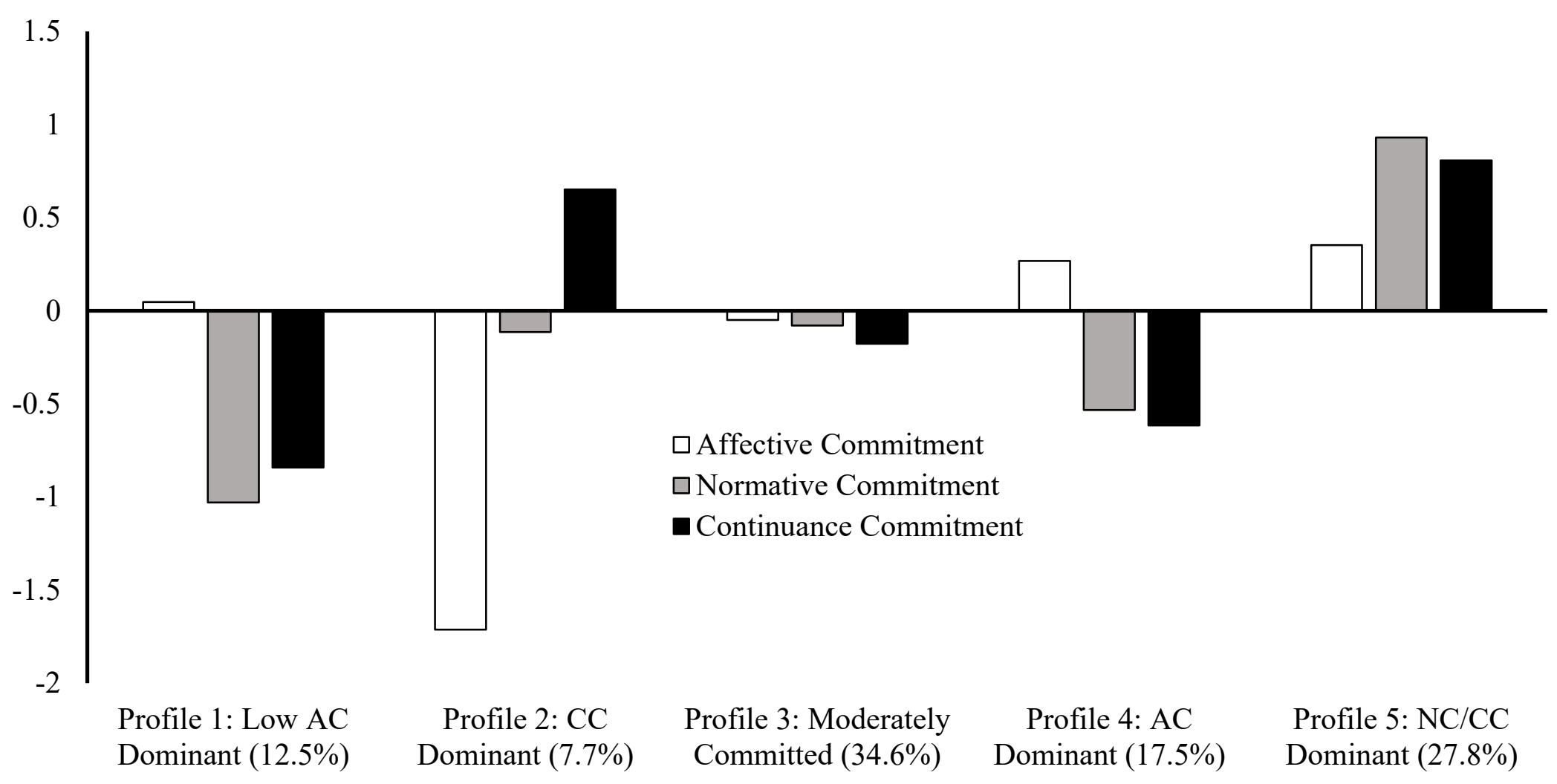

Figure 3. Final 5-Profile solution of distributional similarity.

Note. Profile indicators are factor scores with mean of 0 and a standard deviation of 1. 


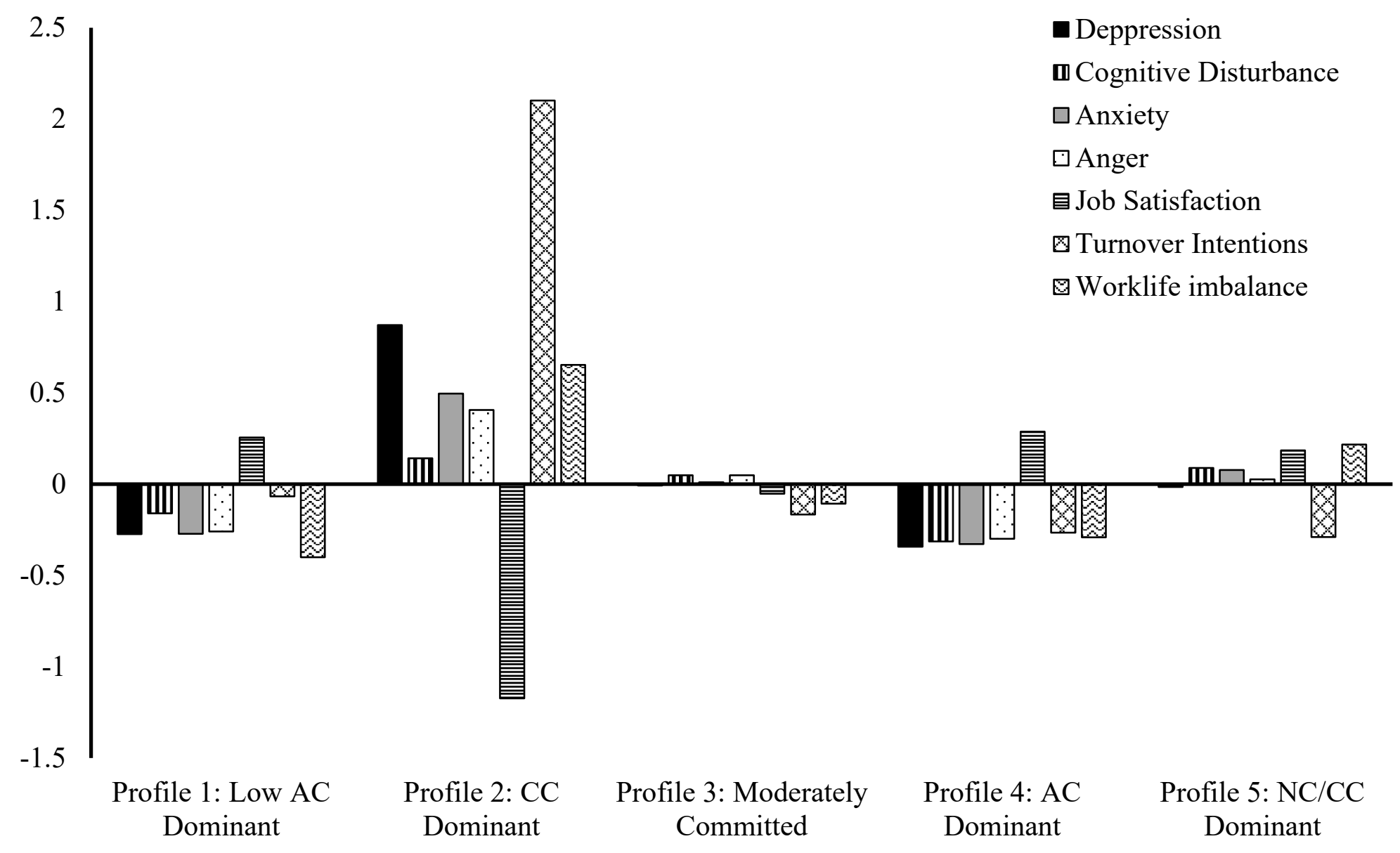

Figure 4. Outcome means for the 5-profile distributional similarity model.

Note. Profile indicators are factor scores with mean of 0 and a standard deviation of 1 . 


\section{Appendix 2: Tables}

Table 1

Goodness-of-Fit Information for the Measurement Models

\begin{tabular}{lccccccc}
\hline Model & $\mathrm{df}$ & $\chi^{2}$ & CFI & TLI & RMSEA & $90 \%$ CI & $\Delta \chi^{2}(\mathrm{df})$ \\
\hline Organizational Commitment & $(\mathbf{A C}, \mathbf{N C}, \mathbf{C C})$ & & & & & \\
Configural & 420 & $788.814^{*}$ & .921 & .906 & .041 & $.036 ; .045$ & \\
Weak & 435 & $796.343^{*}$ & .922 & .911 & .040 & $.035 ; .044$ & $10.712(15)$ \\
Strong & 447 & $807.966^{*}$ & .922 & .914 & .039 & $.035 ; .044$ & $10.417(12)$ \\
Strict & 463 & $814.255^{*}$ & .924 & .919 & .038 & $.034 ; .042$ & $15.368(16)$ \\
Latent V\& CV & 470 & $824.257^{*}$ & .924 & .920 & .038 & $.034 ; .042$ & $10.474(7)$ \\
Latent means & 474 & $825.836^{*}$ & .924 & .921 & .038 & $.033 ; .042$ & $1.961(4)$ \\
\hline Involvement in Decision Process, Transformational Leadership, Relationships with Personnel \\
Configural & 495 & $828.702^{*}$ & .962 & .957 & .035 & $.031 ; .039$ & \\
Weak & 509 & $844.639^{*}$ & .962 & .958 & .035 & $.031 ; .039$ & $15.357(14)$ \\
Strong & 523 & $858.844^{*}$ & .962 & .959 & .034 & $.030 ; .038$ & $13.339(14)$ \\
Strict & 540 & $878.264^{*}$ & .961 & .960 & .034 & $.030 ; .038$ & $22.144(17)$ \\
Latent V \& CV & 546 & $900.312^{*}$ & .960 & .959 & .034 & $.030 ; .038$ & $21.138(6)^{*}$ \\
Latent means & 549 & $906.156^{*}$ & .959 & .958 & .034 & $.030 ; .038$ & $6.010(3)$ \\
\hline Job Satisfaction, Turnover Intentions, Psychological Distress & & & \\
Configural & 1365 & $2239.589^{*}$ & .921 & .911 & .034 & $.032 ; .037$ & \\
Weak & 1386 & $2261.720^{*}$ & .921 & .912 & .034 & $.032 ; .037$ & $25.051(21)$ \\
Weak ETEC & 1387 & $2261.122^{*}$ & .921 & .912 & .034 & $.032 ; .037$ & $.099(1)$ \\
Strong & 1408 & $2280.038^{*}$ & .921 & .914 & .034 & $.031 ; .036$ & $17.729(21)$ \\
Strict & 1436 & $2293.062^{*}$ & .923 & .917 & .033 & $.031 ; .036$ & $27.015(28)$ \\
Latent V \& CV & 1464 & $2318.096^{*}$ & .923 & .919 & .033 & $.030 ; .035$ & $27.547(28)$ \\
Latent means & 1471 & $2328.435^{*}$ & .923 & .919 & .033 & $.030 ; .035$ & $10.276(7)$ \\
\hline
\end{tabular}

Note. ${ }^{*} \mathrm{p}<.01 ;$ df: degrees of freedom; $\chi^{2}=$ chi-square; CFI: comparative fit index; TLI: TuckerLewis index; RMSEA: root mean square approximation; C.I.: $90 \%$ confidence intervals for the RMSEA, $\Delta \chi^{2}$ : Chi-square difference test. 
Table 2

Longitudinally Invariant Standardized Parameter Estimates for the Occupational Commitment Measurement Model

\begin{tabular}{lcccccc} 
& \multicolumn{2}{c}{ Affective Commitment } & \multicolumn{2}{c}{ Normative Commitment } & \multicolumn{2}{c}{ Continuance Commitment } \\
& $\lambda$ & $\delta$ & $\lambda$ & $\delta$ & $\lambda$ & $\delta$ \\
\hline Item 1 & .618 & .460 & .515 & .734 & .674 & .546 \\
Item 2 & .519 & .581 & .703 & .505 & .413 & .830 \\
Item 3 & .701 & .508 & .729 & .469 & .897 & .196 \\
Item 4 & .770 & .406 & .818 & .330 & .856 & .267 \\
Item 5 & .514 & .646 & .832 & .307 & & \\
Item 6 & .821 & .325 & .710 & .495 & & \\
\hline
\end{tabular}

Note. $\lambda$ : factor loading; $\delta$ : item uniqueness; All coefficients are statistically significant $(\mathrm{p} \leq .01)$. 
Table 3

Longitudinally Invariant Standardized Parameter Estimates for the Predictors Measurement Model

\begin{tabular}{|c|c|c|c|c|c|c|}
\hline & \multicolumn{2}{|c|}{ Relationships with Personnel } & \multicolumn{2}{|c|}{ Transformational Leadership } & \multicolumn{2}{|c|}{ Involvement in Decision Process } \\
\hline & $\lambda$ & $\delta$ & $\lambda$ & $\delta$ & $\lambda$ & $\delta$ \\
\hline Item 1 & .883 & .745 & .698 & .512 & .505 & .220 \\
\hline Item 2 & .864 & .308 & .858 & .265 & .832 & .254 \\
\hline Item 3 & .925 & .375 & .849 & .279 & .790 & .145 \\
\hline Item 4 & .905 & .313 & .895 & .198 & .829 & .180 \\
\hline Item 5 & .917 & .779 & .789 & .377 & .470 & .160 \\
\hline Item 6 & & & .823 & .323 & & \\
\hline Item 7 & & & .853 & .273 & & \\
\hline
\end{tabular}

Note. $\lambda$ : factor loading; $\delta$ : item uniqueness; All coefficients are statistically significant $(\mathrm{p} \leq .01)$. 
Table 4

Longitudinally Invariant Standardized Parameter Estimates for the Outcomes CFA Measurement Model

\begin{tabular}{|c|c|c|c|c|c|c|c|c|c|c|c|c|c|c|}
\hline & \multicolumn{2}{|c|}{$\begin{array}{l}\text { Turnover } \\
\text { Intentions }\end{array}$} & \multicolumn{2}{|c|}{$\begin{array}{c}\text { Job } \\
\text { Satisfaction }\end{array}$} & \multicolumn{2}{|c|}{ Depression } & \multicolumn{2}{|c|}{$\begin{array}{c}\text { Cognitive } \\
\text { Disturbance }\end{array}$} & \multicolumn{2}{|c|}{ Anxiety } & \multicolumn{2}{|c|}{ Anger } & \multicolumn{2}{|c|}{$\begin{array}{l}\text { Work-life } \\
\text { Imbalance }\end{array}$} \\
\hline & $\lambda$ & $\delta$ & $\lambda$ & $\delta$ & $\lambda$ & $\delta$ & $\lambda$ & $\delta$ & $\lambda$ & $\delta$ & $\lambda$ & $\delta$ & $\lambda$ & $\delta$ \\
\hline Item 1 & .811 & .342 & .738 & .455 & .694 & .518 & .847 & .283 & .710 & .496 & .636 & .596 & .673 & .548 \\
\hline Item 2 & .820 & .328 & .684 & .532 & .675 & .544 & .914 & .165 & .665 & .558 & .688 & .526 & .813 & .339 \\
\hline Item 3 & .874 & .236 & .782 & .388 & .793 & .371 & & & .790 & .377 & .843 & .289 & .942 & .112 \\
\hline Item 4 & .805 & .352 & .816 & .334 & .571 & .674 & & & & & .697 & .515 & .963 & .074 \\
\hline Item 5 & & & .689 & .525 & .542 & .706 & & & & & & & .851 & .276 \\
\hline
\end{tabular}

Note. $\lambda$ : factor loading; $\delta$ : item uniqueness; All coefficients are statistically significant $(\mathrm{p} \leq .01)$. 
Table 5

Reliability and Correlations for the Variables used in this Study

\begin{tabular}{|c|c|c|c|c|c|c|c|c|c|c|c|c|c|c|c|c|c|c|}
\hline Variables & $\alpha$ & $\omega$ & 1 & 2 & 3 & 4 & 5 & 6 & 7 & 8 & 9 & 10 & 11 & 12 & 13 & 14 & 15 & 16 \\
\hline 1. AC_1 (fs) & .830 & .842 & & & & & & & & & & & & & & & & \\
\hline 2. $\mathrm{AC}_{-} 4(\mathrm{fs})$ & .840 & .842 & $.841 * *$ & & & & & & & & & & & & & & & \\
\hline 3. CC_1 (fs) & .773 & .814 & -.074 & .014 & & & & & & & & & & & & & & \\
\hline 4. CC_4 (fs) & .817 & .814 & $-.164 * *$ & $-.143 * *$ & $.738 * *$ & & & & & & & & & & & & & \\
\hline 5. $\mathrm{NC}_{-} 1$ (fs) & .863 & .867 & $.217 * *$ & $.312 * *$ & $.615^{* *}$ & $.461 * *$ & & & & & & & & & & & & \\
\hline 6. $\mathrm{NC}_{-} 4(\mathrm{fs})$ & .858 & .867 & .044 & $.157 * *$ & $.435 * *$ & $.656^{* *}$ & $.688 * *$ & & & & & & & & & & & \\
\hline 7. $\mathrm{DEC}_{-} 1$ (fs) & .819 & .925 & $.266 * *$ & $.231 * *$ & $-.104 *$ & $-.143 * *$ & $.110^{*}$ & -.018 & & & & & & & & & & \\
\hline 8. $\mathrm{DEC}_{-} 4(\mathrm{fs})$ & .822 & .925 & $.318 * *$ & $.327 * *$ & $-.108^{*}$ & $-.132 * *$ & $.123 * *$ & .039 & $.833 * *$ & & & & & & & & & \\
\hline 9. LEAD_1 (fs) & .934 & .937 & $.280 * *$ & $.231 * *$ & -.080 & $-.117 * *$ & $.124 * *$ & -.009 & $.764 * *$ & $.731^{* *}$ & & & & & & & & \\
\hline 10. LEAD_4 (fs) & .940 & .937 & $.290 * *$ & $.311 * *$ & $-.088^{*}$ & $-.138 * *$ & $.126^{* *}$ & .045 & $.691^{* *}$ & $.832 * *$ & $.824 * *$ & & & & & & & \\
\hline 11. PRS_1 (fs) & .955 & .889 & $.364 * *$ & $.351 * *$ & -.048 & $-.092 *$ & $.140 * *$ & .010 & $.506 * *$ & $.598 * *$ & $.528 * *$ & $.519 * *$ & & & & & & \\
\hline 12. PRS_4 (fs) & .952 & .889 & $.334 * *$ & $.391 * *$ & $-.099 *$ & $-.134 * *$ & .082 & .040 & $.415^{* *}$ & $.649^{* *}$ & $.509^{* *}$ & $.672 * *$ & $.676^{* *}$ & & & & & \\
\hline 13. Sat_1 (fs) & .842 & .860 & $.657 * *$ & $.595 * *$ & -.069 & $-.140 * *$ & $.163 * *$ & .019 & $.339 * *$ & $.365^{* *}$ & $.362 * *$ & $.328 * *$ & $.384 * *$ & $.337^{* *}$ & & & & \\
\hline 14. Sat_4 (fs) & .864 & .860 & $.606 * *$ & $.696 * *$ & -.058 & $-.173 * *$ & $.181 * *$ & .052 & $.275^{* *}$ & $.370 * *$ & $.307 * *$ & $.351 * *$ & $.346^{* *}$ & $.420 * *$ & $.863 * *$ & & & \\
\hline 15. IDQ_1 (fs) & .889 & .897 & $-.578 * *$ & $-.548 * *$ & -.049 & .024 & $-.222 * *$ & $-.088^{*}$ & $-.197 * *$ & $-.263 * *$ & $-.255^{* *}$ & $-.249 * *$ & $-.285^{* *}$ & $-.294 * *$ & $-.560 * *$ & $-.580 * *$ & & \\
\hline 16. IDQ_4 (fs) & .899 & .897 & $-.488 * *$ & $-.557 * *$ & -.055 & -.003 & $-.213 * *$ & $-.136 * *$ & $-.153 * *$ & $-.247 * *$ & $-.208 * *$ & $-.252 * *$ & $-.262 * *$ & $-.307 * *$ & $-.456^{* *}$ & $-.586 * *$ & $.907 * *$ & \\
\hline 17. Dep_1 (fs) & .750 & .792 & $-.367 * *$ & $-.340 * *$ & $.199 * *$ & $.241 * *$ & .017 & $.109 *$ & $-.288 * *$ & $-.287 * *$ & $-.269 * *$ & $-.249 * *$ & $-.260 * *$ & $-.234 * *$ & $-.505 * *$ & $-.440 * *$ & $.330 * *$ & $.289 * *$ \\
\hline 18. Dep_4 (fs) & .809 & .792 & $-.289 * *$ & $-.394 * *$ & $.148 * *$ & $.304 * *$ & -.017 & $.123 * *$ & $-.249 * *$ & $-.319 * *$ & $-.220 * *$ & $-.303 * *$ & $-.210 * *$ & $-.279 * *$ & $-.395^{* *}$ & $-.488 * *$ & $.299 * *$ & $.364 * *$ \\
\hline 19. $\mathrm{CG}_{-} 1(\mathrm{fs})$ & .855 & .874 & $-.204 * *$ & $-.132 * *$ & $.125^{* *}$ & $.156^{* *}$ & .053 & $.114 * *$ & $-.191 * *$ & $-.174 * *$ & $-.165 * *$ & $-.174 * *$ & $-.119 * *$ & $-.092 *$ & $-.363 * *$ & $-.293 * *$ & $.142 * *$ & $.115^{* *}$ \\
\hline 20. CG_4 (fs) & .891 & .874 & $-.206 * *$ & $-.224 * *$ & $.105 *$ & $.205^{* *}$ & -.012 & .072 & $-.194 * *$ & $-.225 * *$ & $-.149 * *$ & $-.235 * *$ & $-.110 *$ & $-.155^{* *}$ & $-.332 * *$ & $-.366 * *$ & $.161 * *$ & $.185 * *$ \\
\hline 21. AX_1 (fs) & .737 & .766 & $-.302 * *$ & $-.293 * *$ & $.186 * *$ & $.262 * *$ & .03 & $.139 * *$ & $-.278 * *$ & $-.270 * *$ & $-.246 * *$ & $-.239 * *$ & $-.223 * *$ & $-.199 * *$ & $-.456 * *$ & $-.418 * *$ & $.261 * *$ & $.235 * *$ \\
\hline 22. AX_4 (fs) & .802 & .766 & $-.248 * *$ & $-.324 * *$ & $.138 * *$ & $.286^{* *}$ & -.006 & $.133 * *$ & $-.242 * *$ & $-.276^{* *}$ & $-.208 * *$ & $-.263 * *$ & $-.173 * *$ & $-.213 * *$ & $-.376^{* *}$ & $-.446 * *$ & $.241 * *$ & $.283 * *$ \\
\hline 23. $A G_{-} 1(\mathrm{fs})$ & .788 & .810 & $-.285 * *$ & $-.240 * *$ & $.138 * *$ & $.196^{* *}$ & .024 & $.122 * *$ & $-.212 * *$ & $-.193 * *$ & $-.212 * *$ & $-.162 * *$ & $-.204 * *$ & $-.137 * *$ & $-.363 * *$ & $-.296 * *$ & $.229 * *$ & $.201 * *$ \\
\hline 24. $\mathrm{AG}_{-} 4(\mathrm{fs})$ & .847 & .810 & $-.237 * *$ & $-.322 * *$ & $.138 * *$ & $.291 * *$ & .008 & $.139 * *$ & $-.187 * *$ & $-.240 * *$ & $-.173 * *$ & $-.238 * *$ & $-.181 * *$ & $-.193 * *$ & $-.303 * *$ & $-.383 * *$ & $.216^{* *}$ & $.278 * *$ \\
\hline 25. Inf_1 (fs) & .925 & .930 & $-.120 * *$ & $-.103 *$ & $.215 * *$ & $.216^{* *}$ & $.168 * *$ & $.180 * *$ & $-.170 * *$ & $-.129 * *$ & $-.183 * *$ & $-.151 * *$ & $-.123 * *$ & $-.109 *$ & $-.246^{* *}$ & $-.234 * *$ & $.197 * *$ & $.187 * *$ \\
\hline 26. Inf_4 (fs) & .935 & .930 & $-.103 *$ & -.077 & $.192 * *$ & $.246^{* *}$ & $.163 * *$ & $.213 * *$ & $-.134 * *$ & -.078 & $-.137 * *$ & $-.100 *$ & -.078 & -.079 & $-.220 * *$ & $-.241 * *$ & $.210 * *$ & $.220 * *$ \\
\hline
\end{tabular}

Note: $* \mathrm{p}<.05 ; * * \mathrm{p}<.01$; fs = time invariant factor scores (with a mean of 0 and a SD of 1 ); time $1=\ldots 1$; time $2=22$. $\alpha$ : alpha coefficient of scale score reliability; $\omega$ : omega coefficient of model-based composite reliability (identical across time wave due to the complete invariance of the measurement models); AC: affective commitment; CC: continuance commitment; NC: normative commitment; DEC: involvement in decision process; LD: transformational leadership; PRS: relationships with personnel; SAT: job satisfaction; IDQ: turnover intentions; DEP: depression; CG: cognitive disturbances; AX: anxiety; AG: irritability; INF: work-life imbalance. 
Table 5 (continued)

\begin{tabular}{lcccccccccc}
\hline Variables & 17 & 18 & 19 & 20 & 21 & 22 & 23 & 24 & 25 & 26 \\
\hline 17. Dep_1 (fs) & & & & & & & & & \\
18. Dep_4 (fs) & $.707^{* *}$ & & & & & & & & \\
19. CG_1(fs) & $.568^{* *}$ & $.427^{* *}$ & & & & & & & \\
20. CG_4(fs) & $.523^{* *}$ & $.642^{* *}$ & $.769^{* *}$ & & & & & & \\
21. AX_1(fs) & $.899^{* *}$ & $.768^{* *}$ & $.607^{* *}$ & $.595^{* *}$ & & & & & \\
22. AX_4(fs) & $.687^{* *}$ & $.926^{* *}$ & $.503^{* *}$ & $.674^{* *}$ & $.865^{* *}$ & & & & \\
23. AG_1(fs) & $.815^{* *}$ & $.550^{* *}$ & $.466^{* *}$ & $.342^{* *}$ & $.807^{* *}$ & $.595^{* *}$ & & & \\
24. AG_4(fs) & $.603^{* *}$ & $.867^{* *}$ & $.401^{* *}$ & $.583^{* *}$ & $.749^{* *}$ & $.864^{* *}$ & $.652^{* *}$ & & & \\
25. Inf_1(fs) & $.343^{* *}$ & $.262^{* *}$ & $.288^{* *}$ & $.262^{* *}$ & $.354^{* *}$ & $.294^{* *}$ & $.243^{* *}$ & $.214^{* *}$ & & \\
26. Inf_4(fs) & $.322^{* *}$ & $.331^{* *}$ & $.261^{* *}$ & $.284^{* *}$ & $.354^{* *}$ & $.359^{* *}$ & $.230^{* *}$ & $.257^{* *}$ & $.875^{* *}$ & \\
\hline
\end{tabular}


Table 6

Results from the Latent Profiles Analyses

\begin{tabular}{|c|c|c|c|c|c|c|c|c|c|c|}
\hline Model & $L L$ & $\# f p$ & S.C. & $\mathrm{AIC}$ & CAIC & $\mathrm{BIC}$ & $\mathrm{ABIC}$ & Entropy & aLMR & BLRT \\
\hline \multicolumn{11}{|l|}{ Latent Profile Analysis Time 1} \\
\hline 1 Profile & -2032.606 & 6 & 1.269 & 4077.212 & 4108.793 & 4102.793 & 4083.747 & $\mathrm{Na}$ & $\mathrm{Na}$ & $\mathrm{Na}$ \\
\hline 2 Profiles & -1758.340 & 13 & 1.442 & 3542.679 & 3611.103 & 3598.103 & 3556.838 & .916 & $\leq .01$ & $\leq .01$ \\
\hline 3 Profiles & -1621.039 & 20 & 1.453 & 3282.079 & 3387.347 & 3367.347 & 3303.862 & .810 & $\leq .01$ & $\leq .01$ \\
\hline 4 Profiles & -1565.271 & 27 & 1.217 & 3184.541 & 3326.653 & 3299.653 & 3213.948 & .807 & $\leq .01$ & $\leq .01$ \\
\hline 5 Profiles & -1513.759 & 34 & 1.088 & 3095.518 & 3274.473 & 3240.473 & 3132.549 & .810 & .062 & $\leq .01$ \\
\hline 6 Profiles & -1480.735 & 41 & 1.090 & 3043.470 & 3259.269 & 3218.269 & 3088.125 & .835 & .021 & $\leq .01$ \\
\hline 7 Profiles & -1448.637 & 48 & 1.065 & 2993.273 & 3245.916 & 3197.916 & 3045.552 & .840 & .049 & $\leq .01$ \\
\hline 8 Profiles & -1420.514 & 55 & 1.040 & 2951.029 & 3240.516 & 3185.516 & 3010.932 & .831 & $\leq .01$ & $\leq .01$ \\
\hline \multicolumn{11}{|l|}{ Latent Profile Analysis Time 2} \\
\hline 1 Profile & -1856.446 & 6 & 1.404 & 3724.891 & 3756.472 & 3750.472 & 3731.426 & $\mathrm{Na}$ & $\mathrm{Na}$ & $\mathrm{Na}$ \\
\hline 2 Profiles & -1622.858 & 13 & 3.020 & 3271.715 & 3340.139 & 3327.139 & 3285.874 & .722 & .410 & $\leq .01$ \\
\hline 3 Profiles & -1495.212 & 20 & 1.564 & 3030.424 & 3135.692 & 3115.692 & 3052.207 & .832 & $\leq .01$ & $\leq .01$ \\
\hline 4 Profiles & -1430.595 & 27 & 1.498 & 2915.189 & 3057.301 & 3030.301 & 2944.596 & .830 & .083 & $\leq .01$ \\
\hline 5 Profiles & -1375.925 & 34 & 1.172 & 2819.850 & 2998.806 & 2964.806 & 2856.881 & .814 & $\leq .01$ & $\leq .01$ \\
\hline 6 Profiles & -1339.624 & 41 & 1.369 & 2761.248 & 2977.047 & 2936.047 & 2805.903 & .819 & .467 & $\leq .01$ \\
\hline 7 Profiles & -1302.226 & 48 & 1.278 & 2700.452 & 2953.095 & 2905.095 & 2752.731 & .799 & .238 & $\leq .01$ \\
\hline 8 Profiles & -1268.864 & 55 & 1.143 & 2647.728 & 2937.214 & 2882.214 & 2707.631 & .815 & .033 & $\leq .01$ \\
\hline \multicolumn{11}{|l|}{ Latent Profile Analysis: 5 Profiles } \\
\hline Configural Similarity & -2892.606 & 68 & 1.203 & 5921.211 & 6279.122 & 6211.122 & 5995.273 & .820 & $\mathrm{Na}$ & $\mathrm{Na}$ \\
\hline Structural Similarity & -2921.408 & 53 & 1.180 & 5948.817 & 6227.777 & 6174.777 & 6006.542 & .772 & $\mathrm{Na}$ & $\mathrm{Na}$ \\
\hline Dispersion Similarity & -2947.639 & 38 & 1.330 & 5971.277 & 6171.287 & 6133.287 & 6012.665 & .767 & $\mathrm{Na}$ & $\mathrm{Na}$ \\
\hline Distributional Similarity & -2955.381 & 34 & 1.425 & 5978.762 & 6157.718 & 6123.718 & 6015.793 & .766 & $\mathrm{Na}$ & $\mathrm{Na}$ \\
\hline \multicolumn{11}{|l|}{ Latent Transition Analysis with Demographics } \\
\hline Effects free across time and profiles & -6314.664 & 330 & .667 & 13289.328 & 15026.250 & 14696.250 & 13648.747 & .945 & $\mathrm{Na}$ & $\mathrm{Na}$ \\
\hline Effects free across time & -6358.730 & 150 & 1.427 & 13017.459 & 13806.969 & 13656.969 & 13180.831 & .939 & $\mathrm{Na}$ & $\mathrm{Na}$ \\
\hline Predictive Similarity & -6387.866 & 114 & 1.617 & 13003.733 & 13603.760 & 13489.760 & 13127.895 & .924 & $\mathrm{Na}$ & $\mathrm{Na}$ \\
\hline Null effects model & -6411.180 & 78 & 1.910 & 12978.360 & 13388.906 & 13310.906 & 13063.314 & .921 & $\mathrm{Na}$ & $\mathrm{Na}$ \\
\hline \multicolumn{11}{|l|}{ Latent Transition Analysis with Predictors } \\
\hline Effects free across time and profiles & -3653.022 & 135 & .599 & 7576.044 & 8286.603 & 8151.603 & 7723.079 & .932 & $\mathrm{Na}$ & $\mathrm{Na}$ \\
\hline Effects free across time points & -3674.978 & 75 & 1.074 & 7499.956 & 7894.710 & 7819.710 & 7581.642 & .922 & $\mathrm{Na}$ & $\mathrm{Na}$ \\
\hline Predictive similarity & -3685.469 & 63 & 1.020 & 7496.939 & 7828.533 & 7765.533 & 7565.555 & .922 & $\mathrm{Na}$ & $\mathrm{Na}$ \\
\hline \multicolumn{11}{|l|}{ Latent Transition Analysis with Outcomes } \\
\hline Effects free across time and profiles & -7407.893 & 124 & 1.761 & 15063.787 & 15716.448 & 15592.448 & 15198.841 & .922 & $\mathrm{Na}$ & $\mathrm{Na}$ \\
\hline Explanatory similarity & -7407.667 & 89 & 1.578 & 14993.334 & 15461.776 & 15372.776 & 15090.268 & .924 & $\mathrm{Na}$ & $\mathrm{Na}$ \\
\hline
\end{tabular}

Explanatory similarity

criterion; ABIC: sample-size adjusted BIC; , S.: scaling correction; AIC: Akaike information criterion, CAIC: consistent AIC, BIC: Bayesian information 


\section{Table 7}

Detailed Results from the Final Latent Profile Analytic Solution (Distributional Similarity).

\begin{tabular}{|c|c|c|c|c|c|c|c|c|c|c|}
\hline & \multicolumn{2}{|c|}{ Profile 1} & \multicolumn{2}{|c|}{ Profile 2} & \multicolumn{2}{|c|}{ Profile 3} & \multicolumn{2}{|c|}{ Profile 4} & \multicolumn{2}{|c|}{ Profile 5} \\
\hline & Mean & CI & Mean & CI & Mean & $\mathrm{CI}$ & Mean & $\mathrm{CI}$ & Mean & CI \\
\hline Affective & .046 & {$[-.166 ; .258]$} & -1.713 & {$[-2.233 ;-1.192]$} & -.049 & {$[-.268 ; .169]$} & .268 & {$[.082 ; .453]$} & .353 & {$[.235 ; .470]$} \\
\hline Normative & -1.030 & {$[-1.056 ;-1.004]$} & -.115 & {$[-.500 ; .270]$} & -.080 & {$[-.236 ; .076]$} & -.533 & {$[-.593 ;-.474]$} & .930 & {$[.759 ; 1.102]$} \\
\hline \multirow[t]{3}{*}{ Continuance } & -.842 & {$[-.859 ;-.826]$} & .652 & {$[.198 ; 1.106]$} & -.177 & {$[-.277 ;-.076]$} & -.616 & {$[-.660 ;-.562]$} & .808 & {$[.609 ; 1.007]$} \\
\hline & \multicolumn{2}{|c|}{ Profile 1} & \multicolumn{2}{|c|}{ Profile 2} & \multicolumn{2}{|c|}{ Profile 3} & \multicolumn{2}{|c|}{ Profile 4} & \multicolumn{2}{|c|}{ Profile 5} \\
\hline & Variance & CI & Variance & CI & Variance & CI & Variance & $\mathrm{CI}$ & Variance & CI \\
\hline Affective & .672 & {$[.335 ; 1.008]$} & 1.213 & {$[.729 ; 1.697]$} & .447 & {$[.317 ; .577]$} & .211 & {$[.077 ; .345]$} & .286 & {$[.212 ; .360]$} \\
\hline Normative & .006 & {$[.002 ; .010]$} & .556 & {$[.268 ; .844]$} & .201 & {$[.161 ; .241]$} & .043 & {$[.022 ; .063]$} & .467 & {$[.391 ; .543]$} \\
\hline Continuance & .003 & {$[.001 ; .005]$} & .869 & {$[.546 ; 1.192]$} & .122 & {$[.084 ; .159]$} & .030 & {$[.024 ; .036]$} & .731 & {$[.627 ; .834]$} \\
\hline
\end{tabular}




\section{Table 8}

Transitions Probabilities for the Final Latent Transition Analysis Model

\begin{tabular}{lccccc}
\hline & \multicolumn{5}{c}{ Transition Probabilities to Time 2 Profiles } \\
Time 1 & Profile 1 & Profile 2 & Profile 3 & Profile 4 & Profile 5 \\
\cline { 2 - 6 } Profile 1 & 81 & 40 & 152 & 96 & 156 \\
Profile 2 & .220 & .036 & .103 & .641 & .000 \\
Profile 3 & .000 & 1.000 & .000 & .000 & .000 \\
Profile 4 & .011 & .000 & .972 & .017 & .000 \\
Profile 5 & .302 & .000 & .108 & .590 & .000 \\
\hline
\end{tabular}

Note. Profile 1: Low AC Dominant; Profile 2: CC Dominant; Profile 3: Moderately

Committed; Profile 4: AC Dominant; Profile 5: NC/CC Dominant. 
Table 9

Results from the Multinomial Logistic and Multiple Regressions Predicting Profile Membership

\begin{tabular}{|c|c|c|c|c|c|c|c|c|c|c|}
\hline & \multicolumn{2}{|c|}{ Profile 1 vs Profile 5} & \multicolumn{2}{|c|}{ Profile 2 vs Profile 5} & \multicolumn{2}{|c|}{ Profile 3 vs Profile 5} & \multicolumn{2}{|c|}{ Profile 4 vs Profile 5} & \multicolumn{2}{|c|}{ Profile 1 vs Profile 4} \\
\hline Predictors & Coeff (SE) & OR & Coeff (SE) & $O R$ & Coeff (SE) & OR & Coeff (SE) & $O R$ & Coeff (SE) & OR \\
\hline Relationship & $-.401(.199)^{*}$ & .670 & $-1.065(.199)^{* *}$ & .345 & $253(.160)$ & .776 & $.255(.177)$ & 1.291 & $-.656(.215)^{* *}$ & .519 \\
\hline Leadership & $.273(.240)$ & 1.314 & $.229(.359)$ & 1.25 & & & & .990 & 284) & 1.326 \\
\hline \multirow[t]{2}{*}{ Involvement } & $-.238(.244)$ & .789 & $-.225(.387)$ & .799 & $.162(.182)$ & 1.175 & $.108(.248)$ & 1.114 & $-.346(.285)$ & .708 \\
\hline & \multicolumn{2}{|c|}{ Profile 2 vs Profile 4} & \multicolumn{2}{|c|}{ Profile 3 vs Profile 4} & \multicolumn{2}{|c|}{ Profile 1 vs Profile 3} & \multicolumn{2}{|c|}{ Profile 2 vs Profile 3} & \multicolumn{2}{|c|}{ Profile 1 vs Profile 2} \\
\hline Predic & Coeff(SE) & $O R$ & Coeff(SE) & OR & Coeff (SE) & $O R$ & Coeff(SE) & OR & Coeff (SE) & OR \\
\hline Relationship & $-1.321(.233)^{* *}$ & .267 & $-.509(.182)^{* *}$ & .601 & $-.148(.198)$ & .863 & $-.812(.223)^{* *}$ & .444 & $.664(.249)^{* *}$ & 1.943 \\
\hline Leadership & $.239(.389)$ & 1.27 & $.027(.249)$ & 1.02 & $.256(.241)$ & 1.292 & $.213(.358)$ & 1.237 & $.043(.382)$ & 1.044 \\
\hline Decision & $-.333(.417)$ & .717 & $.054(.241)$ & 1.05 & $-.399(.237)$ & .671 & $-.387(.377)$ & .679 & $-.013(.417)$ & .987 \\
\hline
\end{tabular}

Note. ${ }^{* *}: p<.01 ; *: p<.05$. SE: standard error of the coefficient; OR: Odds Ratio. The coefficients and OR reflects the effects of the predictors on the likelihood of membership into the first listed profile relative to the second listed profile; Predictors are factor scores with mean of 0 and a standard deviation of 1; Profile $1=$ Low AC Dominant; Profile $2=$ CC Dominant; Profile $3=$ Moderately Committed; Profile 4 = AC Dominant; Profile 5 = NC/CC Dominant. Relationship: Quality of interpersonal relations with other school managers; Leadership: Transformational leadership of the schoolboard; Involvement: Involvement in decision-making processes. 
Table 10

Time-Invariant Associations between Profile Membership and the Outcomes

\begin{tabular}{|c|c|c|c|c|c|c|}
\hline & $\begin{array}{c}\text { Profile } 1 \\
\mathrm{M}[\mathrm{CI}]\end{array}$ & $\begin{array}{c}\text { Profile } 2 \\
\mathrm{M}[\mathrm{CI}]\end{array}$ & $\begin{array}{c}\text { Profile } 3 \\
\mathrm{M}[\mathrm{CI}]\end{array}$ & $\begin{array}{c}\text { Profile } 4 \\
\mathrm{M}[\mathrm{CI}]\end{array}$ & $\begin{array}{c}\text { Profile } 5 \\
\mathrm{M}[\mathrm{CI}]\end{array}$ & Summary of Significant Differences \\
\hline Depression & $\begin{array}{c}-.273 \\
{[-.431 ;-.115]}\end{array}$ & $\begin{array}{c}.871 \\
{[.615 ; 1.127]}\end{array}$ & $\begin{array}{c}-.007 \\
{[-.121 ; .108]}\end{array}$ & $\begin{array}{c}-.342 \\
{[-.448 ;-.236]}\end{array}$ & $\begin{array}{c}-.016 \\
{[-.147 ; .114]}\end{array}$ & $2>3=5>1=4$ \\
\hline Cognitive Disturbance & $\begin{array}{c}-.159 \\
{[-.346 ; .028]}\end{array}$ & {$[-.084 ; .369]$} & {$[-.084 ; .179]$} & $\begin{array}{c}-.313 \\
{[-.428 ;-.198]}\end{array}$ & $\begin{array}{c}.088 \\
{[-.055 ; .231]}\end{array}$ & $2=5>1=4 ; 2=3=5>4 ; 1=3$ \\
\hline Anxiety & $\begin{array}{c}-.272 \\
{[-.457 ;-.087]}\end{array}$ & $\begin{array}{c}.496 \\
{[.253 ; .739]}\end{array}$ & $\begin{array}{c}.01 \\
{[-.113 ; .132]}\end{array}$ & $\begin{array}{c}-.328 \\
{[-.458 ;-.199]}\end{array}$ & $\begin{array}{c}.077 \\
{[-.067 ; .221]}\end{array}$ & $2>3=5>1=4$ \\
\hline Anger & $\begin{array}{c}-.259 \\
{[-.423 ;-.096]}\end{array}$ & $\begin{array}{c}.407 \\
{[.169 ; .645]}\end{array}$ & $\begin{array}{c}.048 \\
{[-.068 ; .163]}\end{array}$ & $\begin{array}{c}-.3 \\
{[-.400 ;-.200]}\end{array}$ & $\begin{array}{c}.027 \\
{[-.108 ; .162]}\end{array}$ & $2>3=5>1=4$ \\
\hline Job Satisfaction & $\begin{array}{c}.255 \\
{[.071 ; .440]}\end{array}$ & $\begin{array}{c}-1.174 \\
{[-1.494 ;-.853]}\end{array}$ & $\begin{array}{c}-.052 \\
{[-.18 ; .077]}\end{array}$ & $\begin{array}{c}.288 \\
{[.168 ; .407]}\end{array}$ & $\begin{array}{c}.185 \\
{[.069 ; .302]}\end{array}$ & $4=5=1>3>2$ \\
\hline Turnover Intentions & $\begin{array}{c}-.066 \\
{[-.310 ; .177]}\end{array}$ & $\begin{array}{c}2.102 \\
{[1.859 ; 2.345]}\end{array}$ & $\begin{array}{c}-.166 \\
{[-.266 ;-.066]}\end{array}$ & $\begin{array}{c}-.265 \\
{[-.375 ;-.154]}\end{array}$ & $\begin{array}{c}-.29 \\
{[-.363 ;-.217]}\end{array}$ & $2>1=3=4 ; 2>1=5=4 ; 3>5$ \\
\hline Work-life Imbalance & $\begin{array}{c}-.4 \\
{[-.591 ;-.210]}\end{array}$ & $\begin{array}{c}.654 \\
{[.402 ; .906]}\end{array}$ & $\begin{array}{c}-.107 \\
{[-.258 ; .043]}\end{array}$ & $\begin{array}{c}-.292 \\
{[-.483 ;-.102]}\end{array}$ & $\begin{array}{c}.217 \\
{[.087 ; .347]}\end{array}$ & $2>5>3>1 ; 2>5>4=1 ; 3=4$ \\
\hline
\end{tabular}

Note. M: Mean; [CI]: 95\% Confidence Interval; Outcomes are factor scores with mean of 0 and a standard deviation of 1 ; Profile $1=$ Low AC Dominant; Profile $2=$ CC Dominant; Profile $3=$ Moderately Committed; Profile $4=$ AC Dominant; Profile $5=$ NC/CC Dominant. 